\title{
The psychosocial determinants of quality of life in breast cancer survivors: a scoping review
}

\author{
Michael G. Culbertson ${ }^{1}$, Kathleen Bennett ${ }^{1}$, Catherine M. Kelly ${ }^{2}$, Linda Sharp ${ }^{3}$ and Caitriona Cahir ${ }^{1 *}$ (D)
}

\begin{abstract}
Background: Breast cancer care today involves state-of-the-art biomedical treatment but can fail to address the broader psychosocial and quality-of-life (QoL) issues associated with the transition to breast cancer survivorship. This scoping review examines the evidence on the influence of psychosocial determinants on QoL in breast cancer survivors.

Methods: Scoping review methodology was used to: (1) identify the research question(s); (2) identify relevant studies; (3) undertake study selection; (4) extract data; (5) collate, summarise and report the results.

Results: A total of 33 studies met the inclusion criteria. The majority of studies were conducted in the US ( $n=22$, $67 \%)$ and were mainly cross-sectional $(n=26,79 \%)$. Sixteen psychosocial determinants of QoL were identified. Social support $(n=14,42 \%)$, depression $(n=7,21 \%)$ and future appraisal and perspective $(n=7,21 \%)$ were the most frequently investigated determinants. Twelve different QoL measures were used. A range of different measurement tools were also used per psychosocial determinant (weighted average $=6$ ). The 14 studies that measured the influence of social support on QoL employed 10 different measures of social support and 7 different measures of QoL. In general, across all 33 studies, a higher level of a positive influence and a lower level of a negative influence of a psychosocial determinant was associated with a better QoL e.g. higher social support and lower levels of depression were associated with a higher/better QoL. For some determinants such as spirituality and coping skills the influence on QoL varied, but these determinants were less commonly investigated.

Conclusion: Consensus around measures of QoL and psychological determinants would be valuable and would enable research to determine the influence of psychosocial determinants on QoL adequately. Research in other healthcare settings beyond the US is required, in order to understand the influence of organisation and follow-up clinical and supportive care on psychosocial determinants and QoL and to improve the quality of care in breast cancer survivors.
\end{abstract}

Keywords: Breast cancer, Survivorship, Quality of life, Psychosocial, Scoping review

\footnotetext{
* Correspondence: caitrionacahi@@rcsi.ie

${ }^{1}$ Division of Population Health Sciences, Royal College of Surgeons in Ireland,

Beaux Lane House, Mercer Street, Dublin 2, Ireland

Full list of author information is available at the end of the article
}

(C) The Author(s). 2020 Open Access This article is licensed under a Creative Commons Attribution 4.0 International License, which permits use, sharing, adaptation, distribution and reproduction in any medium or format, as long as you give appropriate credit to the original author(s) and the source, provide a link to the Creative Commons licence, and indicate if changes were made. The images or other third party material in this article are included in the article's Creative Commons licence, unless indicated otherwise in a credit line to the material. If material is not included in the article's Creative Commons licence and your intended use is not permitted by statutory regulation or exceeds the permitted use, you will need to obtain permission directly from the copyright holder. To view a copy of this licence, visit http://creativecommons.org/licenses/by/4.0/ The Creative Commons Public Domain Dedication waiver (http://creativecommons.org/publicdomain/zero/1.0/) applies to the data made available in this article, unless otherwise stated in a credit line to the data. 


\section{Background}

In recent years, with earlier diagnosis and better treatment options, breast cancer survival in women has increased steadily and 5-year net survival in high income countries is now 85-90\% [1]. This means that millions of women worldwide are now living with, and beyond, a breast cancer diagnosis; the 5 year prevalence of breast cancer is approximately seven million globally [2, 3]. The concept of breast cancer survivorship encompasses the wider physical, psychological, social and economic issues of breast cancer $[4,5]$. The transition from breast cancer patient to breast cancer survivorship brings numerous uncertainties for women [6]. The end of hospital-focused cancer treatment typically includes the loss of the safety net of active medical treatment, a resumption or alteration of former roles within and outside the home, a decline in interpersonal support and ongoing physical and psychological effects of diagnosis and treatment, such as fatigue, sleep disturbance, sexual dysfunction, urinary/bowel problems, and cognitive problems [7, 8]. However, while breast cancer care today often provides state-of-the-art biomedical treatment, it can fail to address the broader psychosocial and qualityof-life (QoL) issues associated with survivorship [9].

Psychosocial factors have been defined as any exposure that may influence a physical health outcome through a psychological mechanism [10]. Psychosocial factors can include depression and other emotional problems, psychological traits and disruptions in the social environment, all of which can compromise the effectiveness of health care and adversely impact breast cancer survivors' return to good health [9]. Major depression, for example, is substantially more common in people with cancer than the general population and mostly goes untreated in the outpatient setting [11]. There is some evidence that psychosocial factors are associated with impairments in QoL in breast cancer survivors [8]. High social isolation and lack of social support have been reported to be associated with a lower QoL in breast cancer survivors [12]. In contrast, personality attributes such as optimism (i.e. general expectancy for positive outcomes) and use of active coping strategies such as problem solving, identifying benefits in the experience and expressing cancer-related emotions are all associated with greater psychological adjustment and an improved QoL [13].

Some studies have indicated that breast cancer survivors have a significantly lower QoL, including lower physical, functional, emotional and social well-being compared to control-matched healthy populations and experience clinically relevant restrictions in several QoL dimensions 10 years after diagnosis, with restrictions in role, cognitive and social functioning and fatigue increasing over time $[12,14]$. While other studies have found that 10 years after diagnosis, many women report having a new meaning to their lives and healthier lifestyles, with long-term survivors having similar or improved QoL levels when compared to age-matched controls who have never had breast cancer $[15,16]$. To inform survivorship care planning, it would be valuable to better understand which psychosocial factors are associated with improved or worsened QoL in breast cancer survivorship. Such an understanding would inform evidence-based psychosocial care and enable the development of targeted interventions to enhance QoL and reduce long term psychological and physical morbidity $[6,17]$. This scoping review, therefore, examines the evidence on the influence of psychosocial determinants on QoL in breast cancer survivors.

\section{Methods}

This scoping review seeks to identify the current literature published in this field, examine how the research was conducted and identify the key factors related to this topic and gaps in knowledge [18]. The scoping review framework of Arksey and O'Malley [19] and later advanced by Levac, Colquhoun [20] was used to guide the current study. This framework includes five stages: (1) identifying the research question(s); (2) identifying relevant studies; (3) study selection; (4) data extraction; (5) collation, summarising and reporting the results [19].

\section{Identifying the research question}

This scoping review was developed to describe the nature, number and scope of published research articles measuring the association between psychosocial determinants and QoL in breast cancer survivors.

\section{Identifying relevant studies}

A systematic literature search of the databases, PubMed, Embase, PsycINFO, and CINAHL was conducted of all articles published between 01/01/1998 and 31/12/2018. The electronic search strategy included MeSH headings, key words and their derivatives "breast cancer, survivor, quality of life" (Appendix). The terms and the search criteria were developed and tested with a medical librarian. All articles were downloaded into Endnote and duplicates were removed.

\section{Study selection}

The titles and abstracts of all identified studies were screened by an independent team of reviewers. One reviewer independently applied the inclusion criteria (Table 1) to each abstract and a random sample of $75 \%$ of the abstracts were reviewed independently by a second reviewer. The review team met to compare screened abstracts and any differences were resolved through consultation with a third reviewer. 
Table 1 Study inclusion and exclusion criteria

\begin{tabular}{|c|c|c|}
\hline Study characteristics & Inclusion criteria & Exclusion criteria \\
\hline \multicolumn{3}{|l|}{ Abstract Criteria } \\
\hline Participants & $\begin{array}{l}\text { Women } \\
\text { Aged 18+ } \\
\text { Breast cancer survivor (post-treatment) }\end{array}$ & Initial diagnosis of breast cancer/pre-cancer treatment \\
\hline Study Design & $\begin{array}{l}\text { Observational studies e.g. retrospective or prospective } \\
\text { cohort studies, cross-sectional studies }\end{array}$ & $\begin{array}{l}\text { Systematic reviews, randomised controlled trials of intervention } \\
\text { or treatment studies }\end{array}$ \\
\hline $\begin{array}{l}\text { Outcome Measure- } \\
\text { quality of life (QoL) }\end{array}$ & $\begin{array}{l}\text { Overall QoL } \\
\text { Physical well-being } \\
\text { Emotional well-being } \\
\text { Functional well-being } \\
\text { Social well-being }\end{array}$ & QoL not reported in the abstract \\
\hline $\begin{array}{l}\text { Psychosocial } \\
\text { Determinants }\end{array}$ & Psychosocial determinants & $\begin{array}{l}\text { Clinical, treatment, or socio-demographic determinants only re- } \\
\text { ported in the abstract }\end{array}$ \\
\hline Publication & $\begin{array}{l}\text { Peer-Reviewed Journal } \\
\text { Published in } \\
\text {-the last } 20 \text { years } \\
\text {-in English }\end{array}$ & $\begin{array}{l}\text { Doctoral Dissertation } \\
\text { Conference proceeding e.g. abstract, poster }\end{array}$ \\
\hline \multicolumn{3}{|l|}{ Full Text Criteria } \\
\hline Population & $\begin{array}{l}\text { Women } \\
\text { Aged } 18+ \\
\text { Stage I-III breast cancer (non-metastatic) } \\
\text { Completed breast cancer treatment } \\
\text { Breast cancer survivor (post-treatment) }\end{array}$ & $\begin{array}{l}\text { Initial diagnosis of breast cancer/pre-cancer treatment } \\
\text { Metastatic breast cancer or Ductal Carcinoma in situ } \\
\text { Currently receiving breast cancer treatment (e.g. chemotherapy, } \\
\text { radiotherapy, excluding endocrine therapy) } \\
\text { Participants of a clinical trial }\end{array}$ \\
\hline $\begin{array}{l}\text { Outcome Measure } \\
\text { (QoL) }\end{array}$ & $\begin{array}{l}\text { Validated QoL measure } \\
\text { Generic and specific to breast cancer } \\
\text { Overall/global QoL }\end{array}$ & $\begin{array}{l}\text { Non-validated QoL measure (developed by authors) } \\
\text { Aspects of QoL e.g. emotional well-being, depression }\end{array}$ \\
\hline $\begin{array}{l}\text { Psychosocial } \\
\text { Determinants }\end{array}$ & $\begin{array}{l}\text { At least one modifiable psychosocial determinants, e.g. } \\
\text { depression, social support }\end{array}$ & $\begin{array}{l}\text { Clinical, treatment, or socio-demographic determinants only } \\
\text { Non-modifiable behavioural determinants only }\end{array}$ \\
\hline Publication & $\begin{array}{l}\text { Peer-Reviewed Journal } \\
\text { Published in } \\
\text {-the last } 20 \text { years } \\
\text {-in English }\end{array}$ & $\begin{array}{l}\text { Doctoral Dissertation } \\
\text { Conference proceeding abstract or poster }\end{array}$ \\
\hline
\end{tabular}

The inclusion criteria were then refined and a more detailed set of criteria was developed for the full text review process (Table 1). The breast cancer survivorship definition was refined to only include women who had completed their hospital-focused breast cancer treatment e.g., women had to be post-surgery, chemotherapy and radiotherapy treatments (if applicable). The criteria for the QoL measure was refined to include only validated measures of overall QoL (e.g. FACT-B, EORTC QLQ-C30) [21, 22]. At least one of the psychosocial determinants measured had to be potentially modifiable (e.g. depression, social support). Two reviewers independently reviewed the full texts of all the identified abstracts using these more detailed inclusion criteria. The reference lists of eligible studies were also reviewed to identify any further studies that had been missed in the electronic searches.

\section{Data extraction}

After reading the full-texts of each study to be included in the review, two researchers independently extracted the following data: author(s), year of publication, study design, study location, participant characteristics, time period, psychosocial determinant(s) and how they were measured, QoL outcome and how it was measured and the main findings and any adjustments for covariates. Data was initially extracted from the first 5 studies and compared by the two reviewers to ensure consistency.

\section{Collating and summarising the data}

The data from the included studies was collated by both psychosocial determinants and QoL measures to provide both a descriptive and numerical summary of the findings and to answer the following four research questions;

1. What are the main psychosocial determinants of QoL in breast cancer survivors that have been investigated to date?

2. What are the most frequently used measurement tools to assess QoL in breast cancer survivors?

3. Which psychosocial determinants measurement tools were used and how frequently were they used per individual QoL measures? 
4. What is the influence of these psychosocial determinants on QoL in breast cancer survivors?

\section{Results}

\section{Study population}

The study selection process is outline in Fig. 1. The four databases yielded 7516 citations, which reduced to 6071 after removing duplicates. Of these, 58 full-texts were deemed potentially eligible and reviewed in full text. Of these, 33 studies were eligible for inclusion in this scoping review.

The majority of included studies $(n=26,79 \%)$ employed a cross-sectional design; the remaining 7 studies (21\%) assessed and compared QoL at various different time points post diagnosis e.g. short term at 6,12 and 18 months [23, 24], medium term 2-4 years [25-27] and longer term 5-13 years later [13, 28]. Most studies were conducted in the United States $(n=22,67 \%)$, with the remainder from China $(n=3,9 \%)$, Germany $(n=2$, 6\%), and single studies in Australia, Taiwan, Malaysia, Japan, Korea and Austria respectively. Sample size ranged from 51 to 2671 participants; the average was $418[29,30]$. The average age of participants was mid40 s to mid-50s, but ranged from 18 years to 96 years. The time period since completing breast cancer treatment varied greatly; some studies assessed the psychosocial determinants of QoL 6 months to 1 year posttreatment [28, 31], while other studies included participants who completed treatment up to 35 years previously [32].

\section{Identifying psychosocial determinants of QoL in breast cancer survivors}

The eligible studies reported on 16 possible psychosocial determinants of QoL (Table 2). The most prevalent psychosocial determinants investigated were social support (investigated in 14 studies), depression (7 studies) and future appraisal and perspective (7 studies). Five studies assessed coping, optimism and stress determinants and 4 studies assessed spirituality. Three studies looked at anxiety, confidence and self-efficacy and impact of events. Two studies investigated post-traumatic growth and there were single studies for positive and negative affect, cognitive symptoms, work limitations and health care system factors.

\section{QoL measures}

There were 12 different validated QoL outcome measures utilised by the various studies in the scoping review (Table 3). The Functional Assessment of Cancer Breast Cancer (FACT-B) was the most frequently used QoL measure (13 studies) [23-26, 30, 33, 35, 38, 41, 4749, 54]. Two studies applied the Functional Assessment of Cancer Therapy - General (FACT-G), without the Breast Cancer Subscale (BC Subscale) [31, 42]. The SF36 was used in 8 studies [27, 33, 36, 37, 47, 50, 52, 53]. The EORTC QLQ-C30 was used to assess QoL in 6

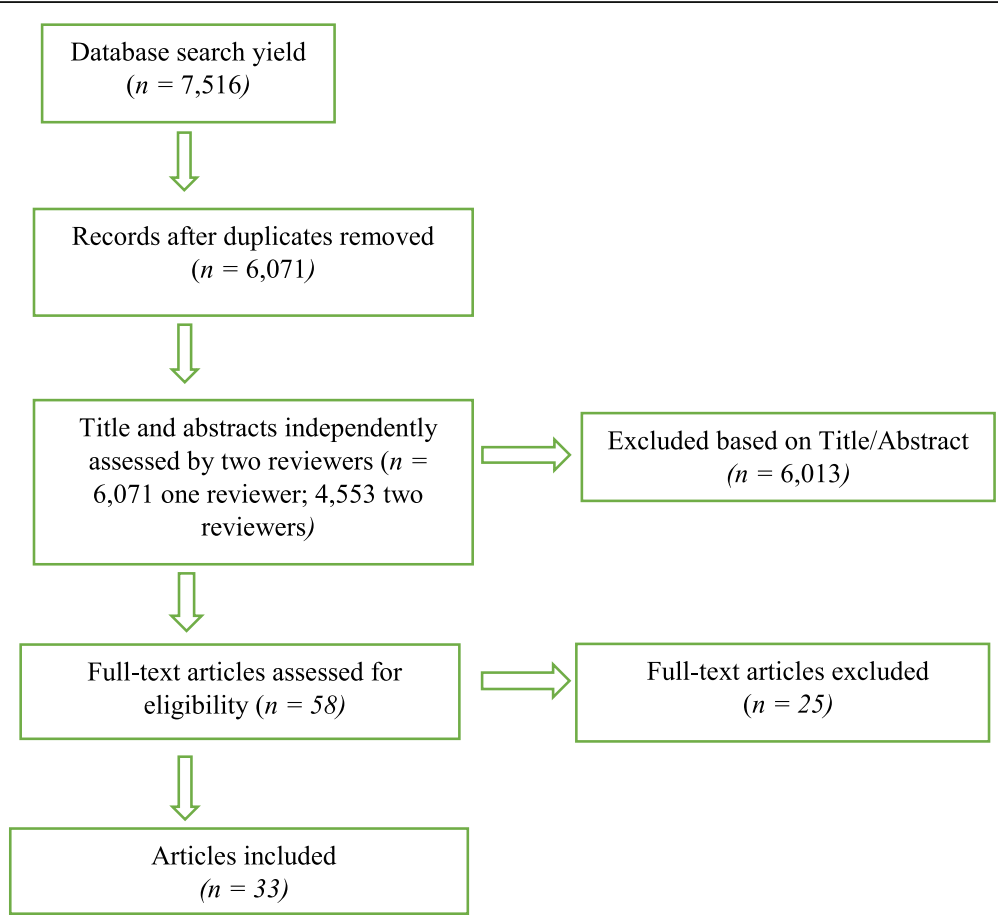

Fig. 1 PRISMA diagram of selection of studies 


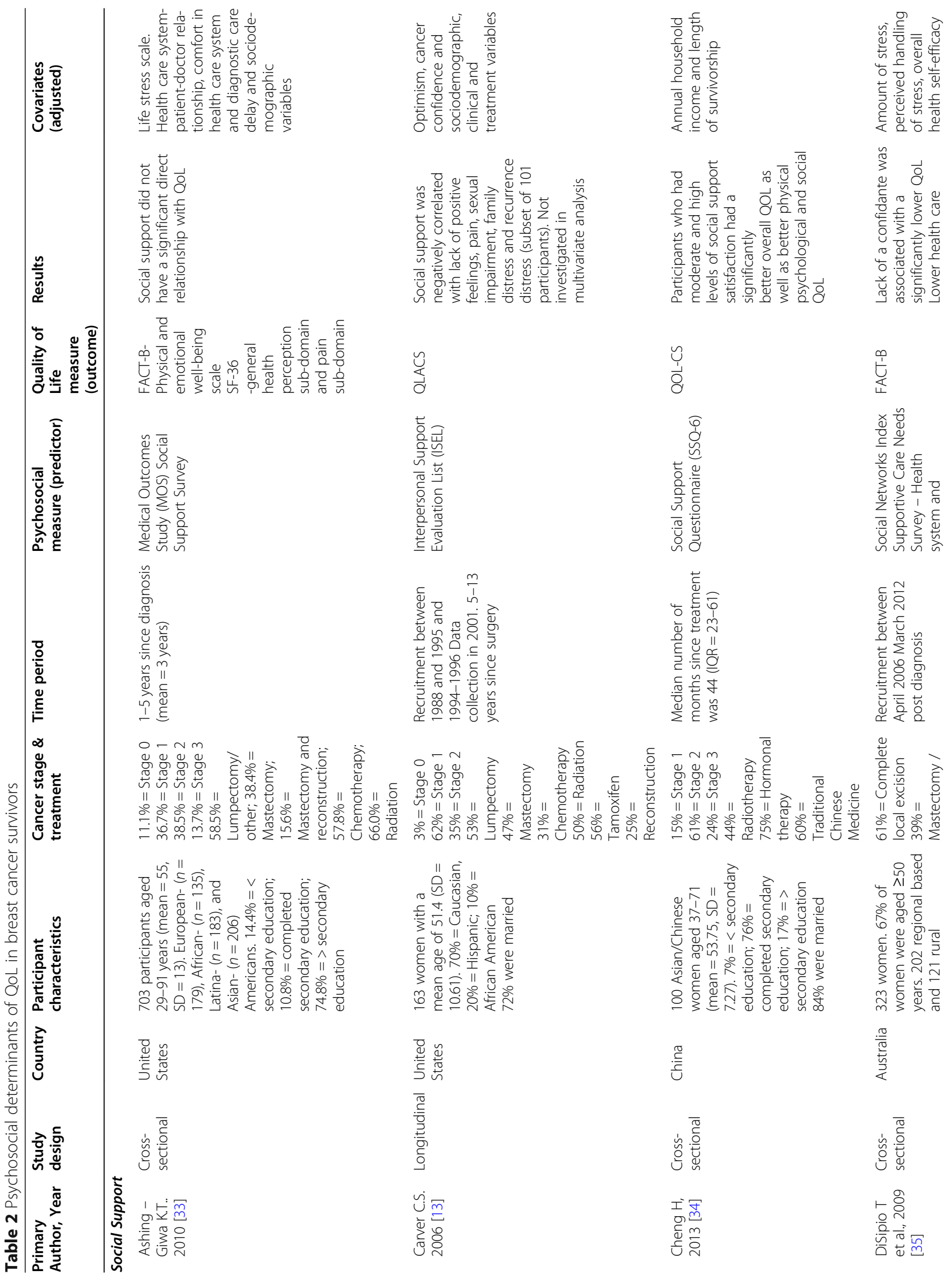




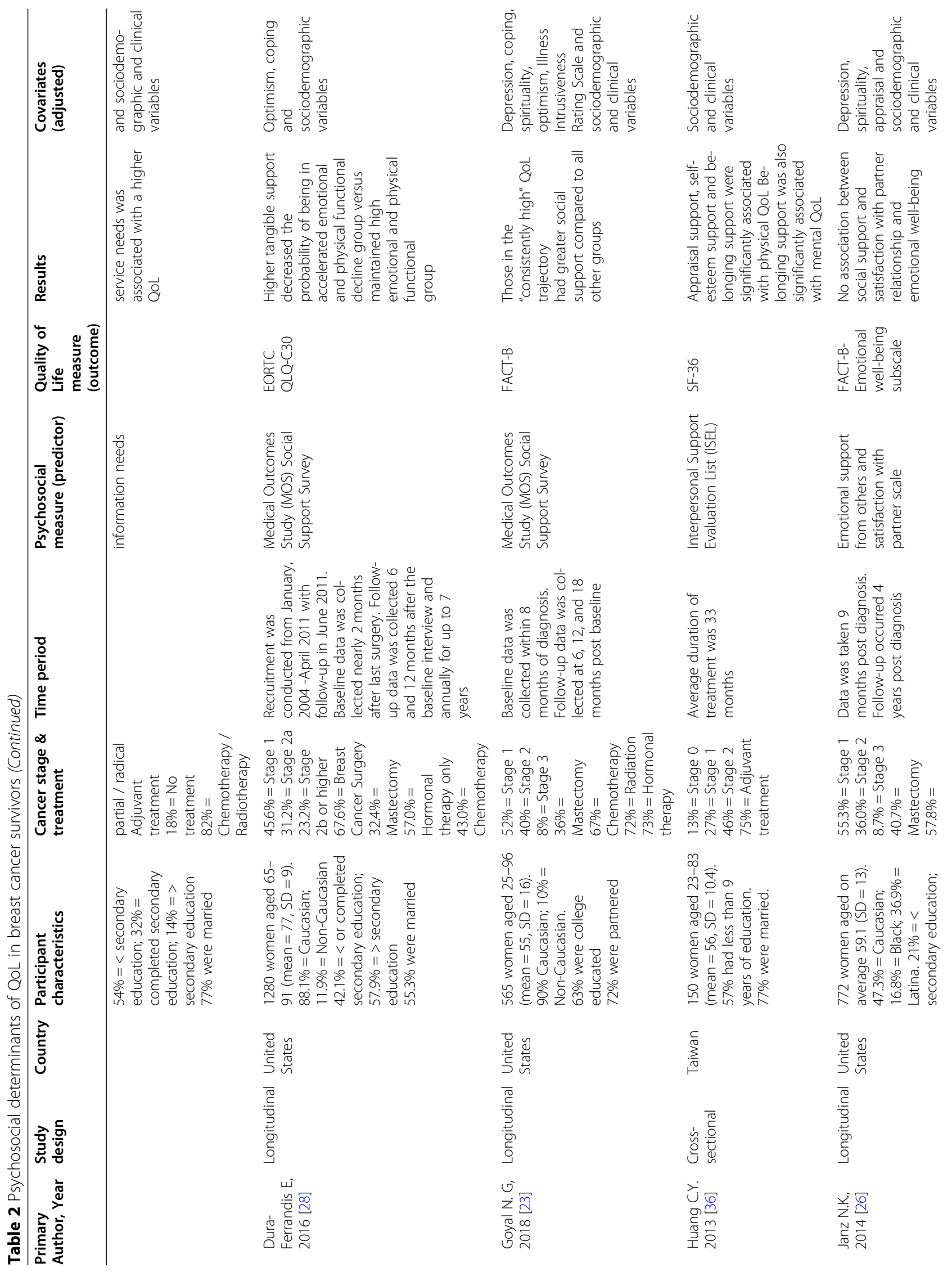




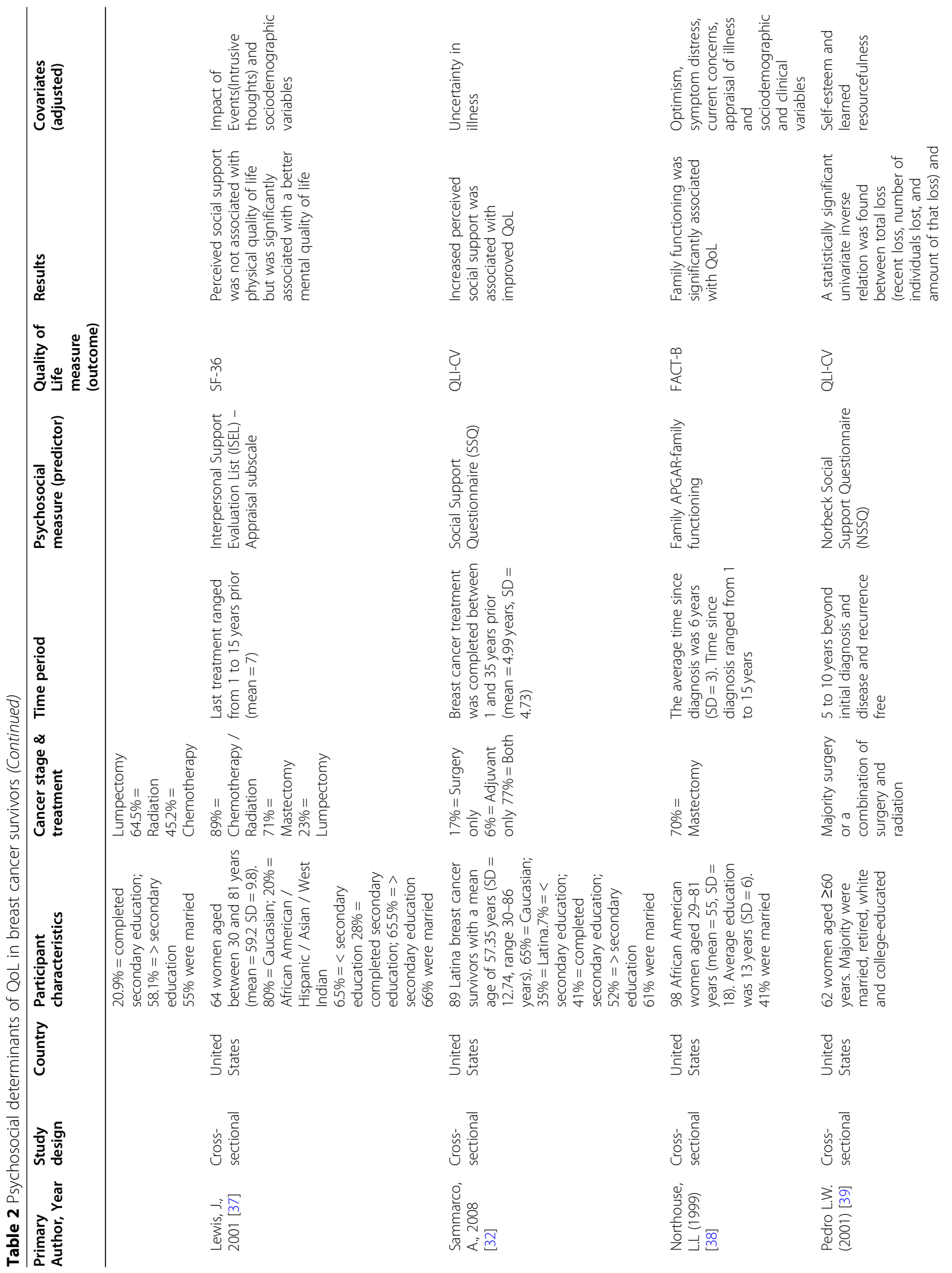




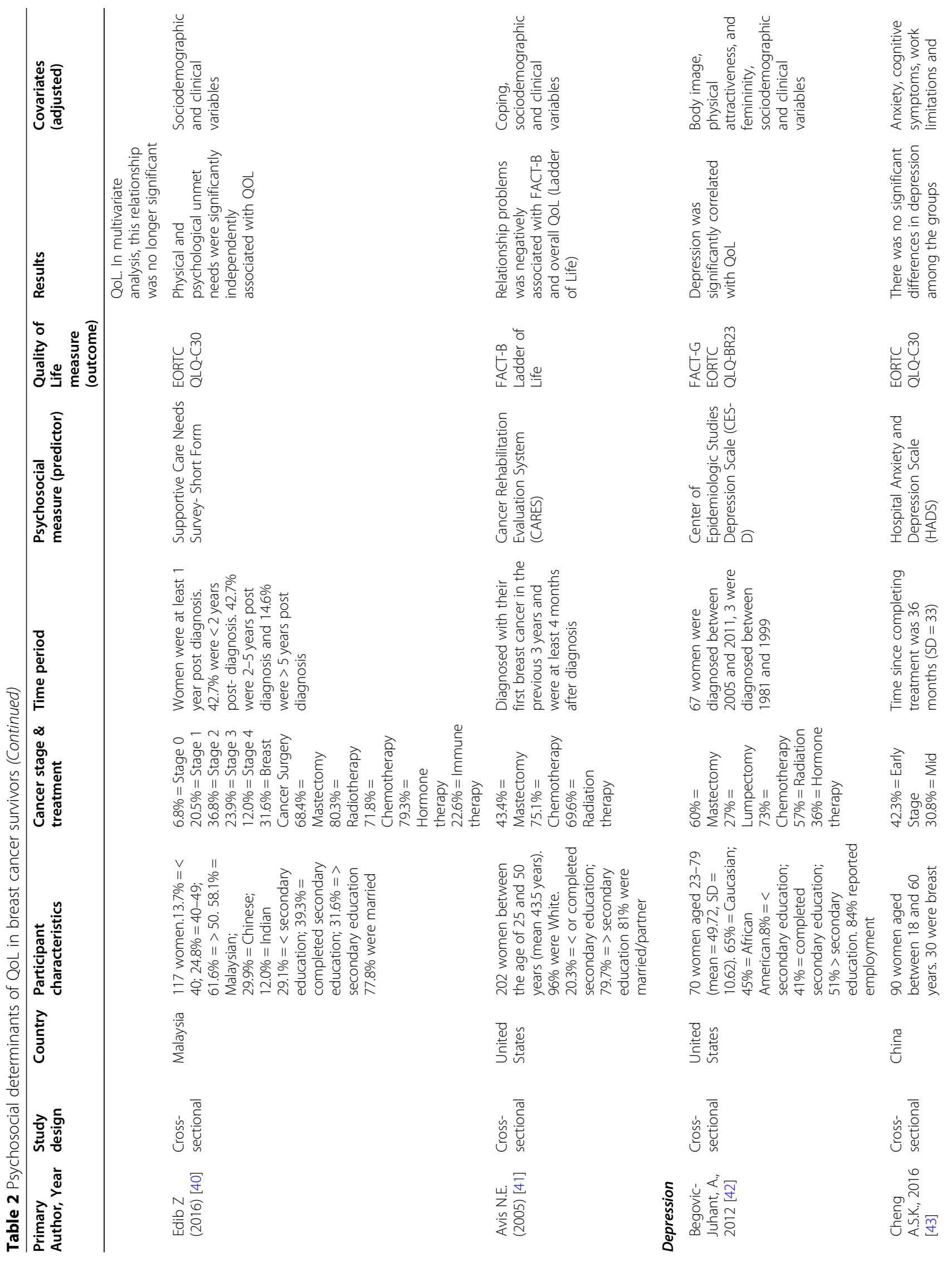




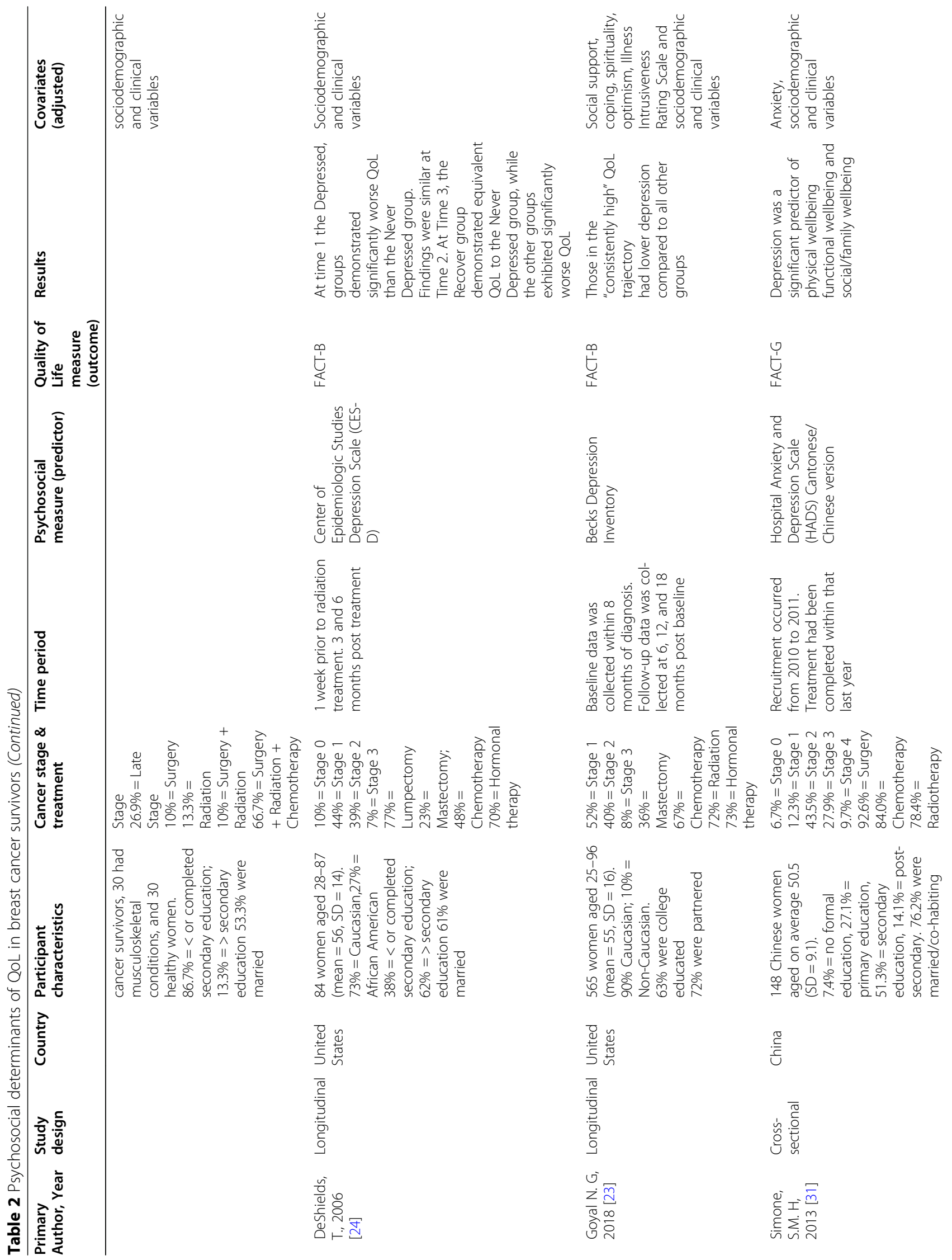




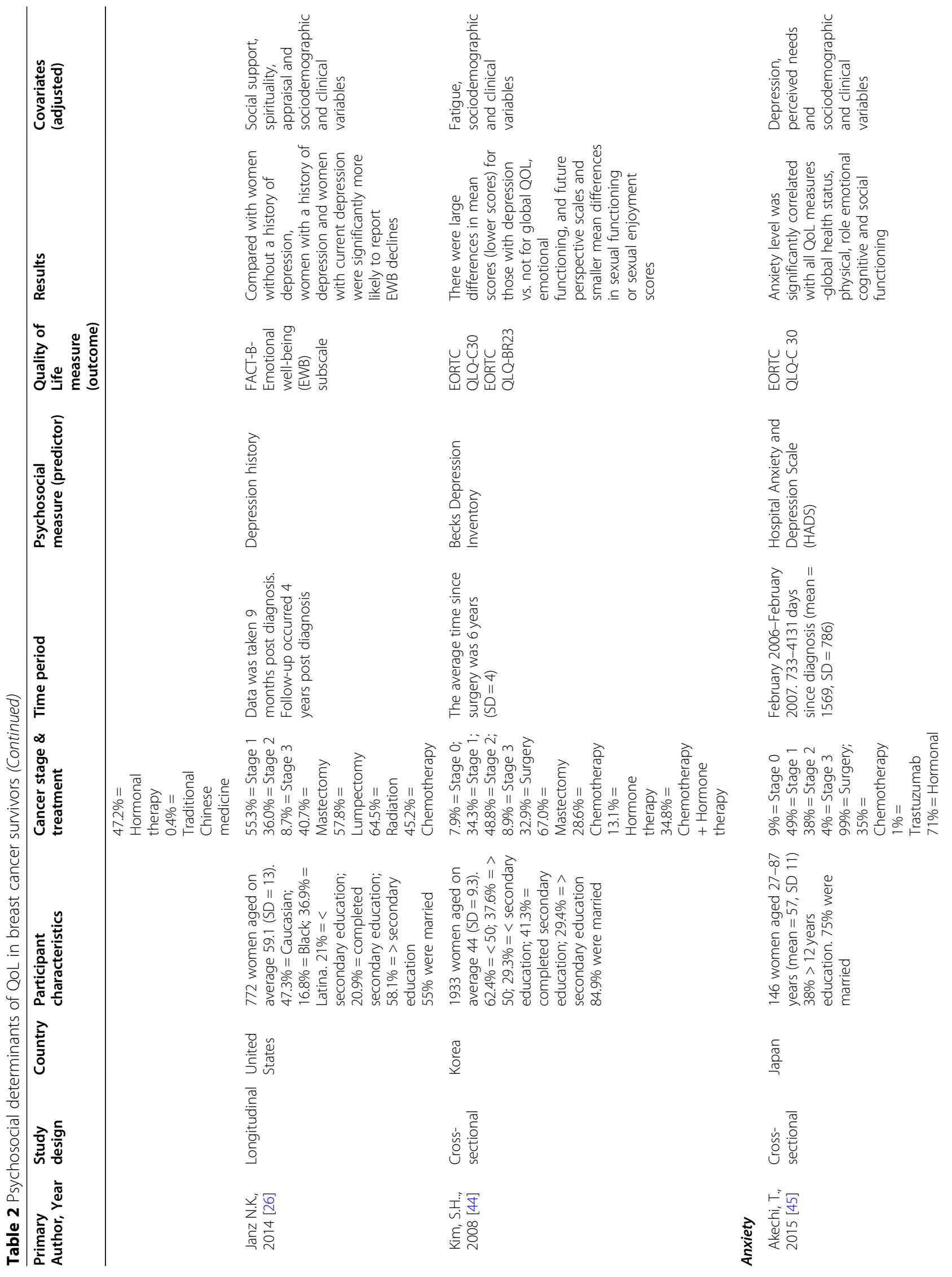




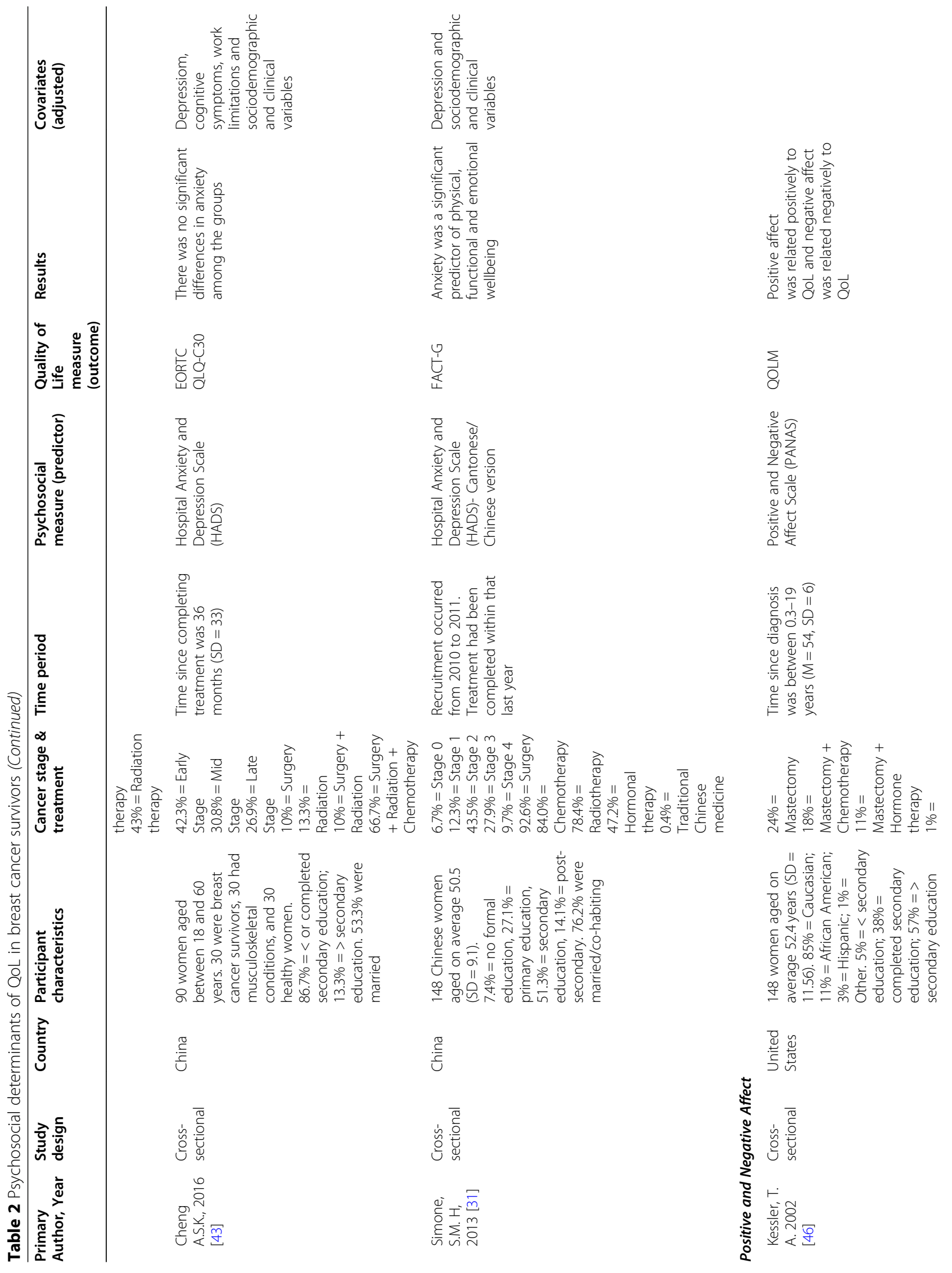




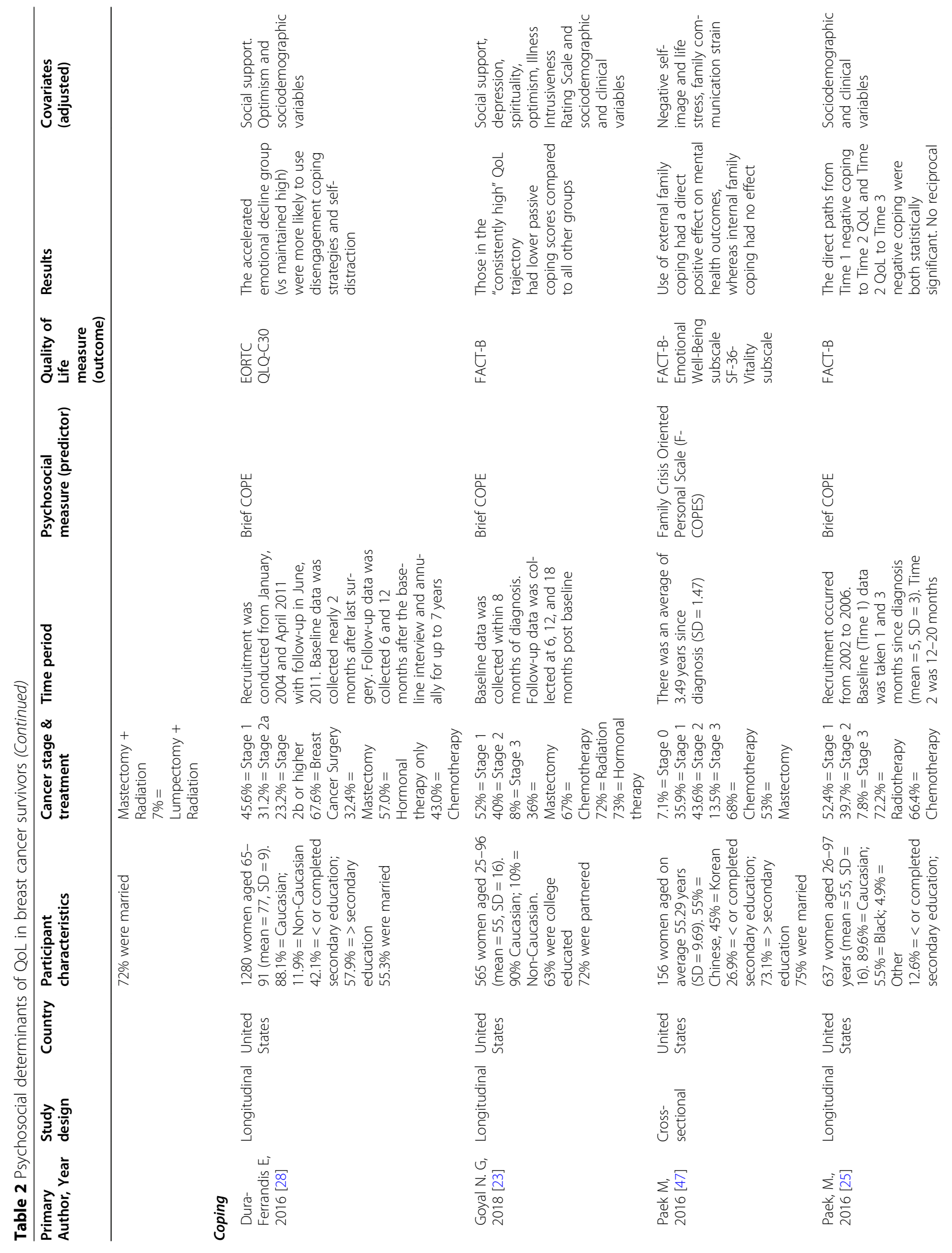




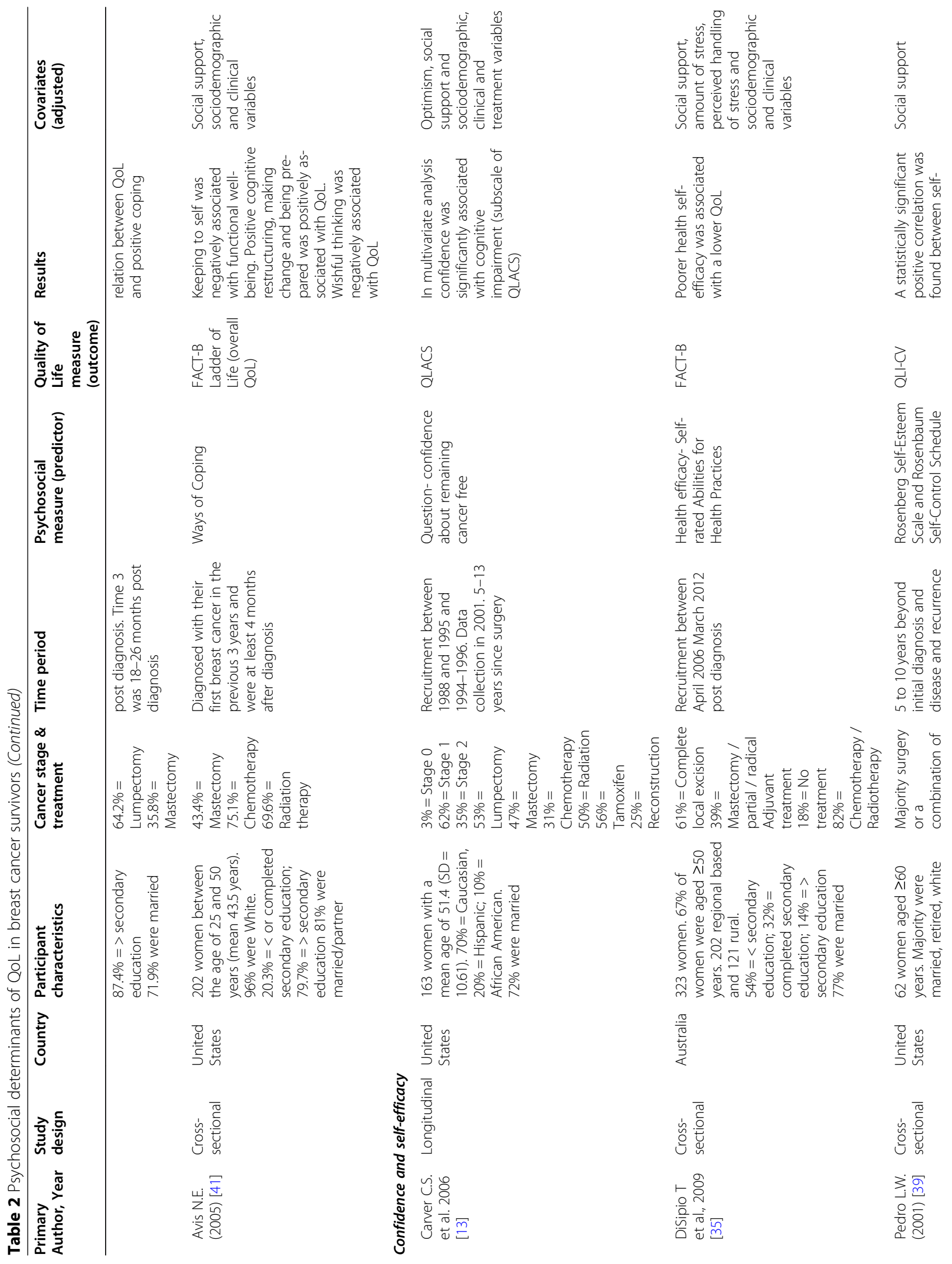




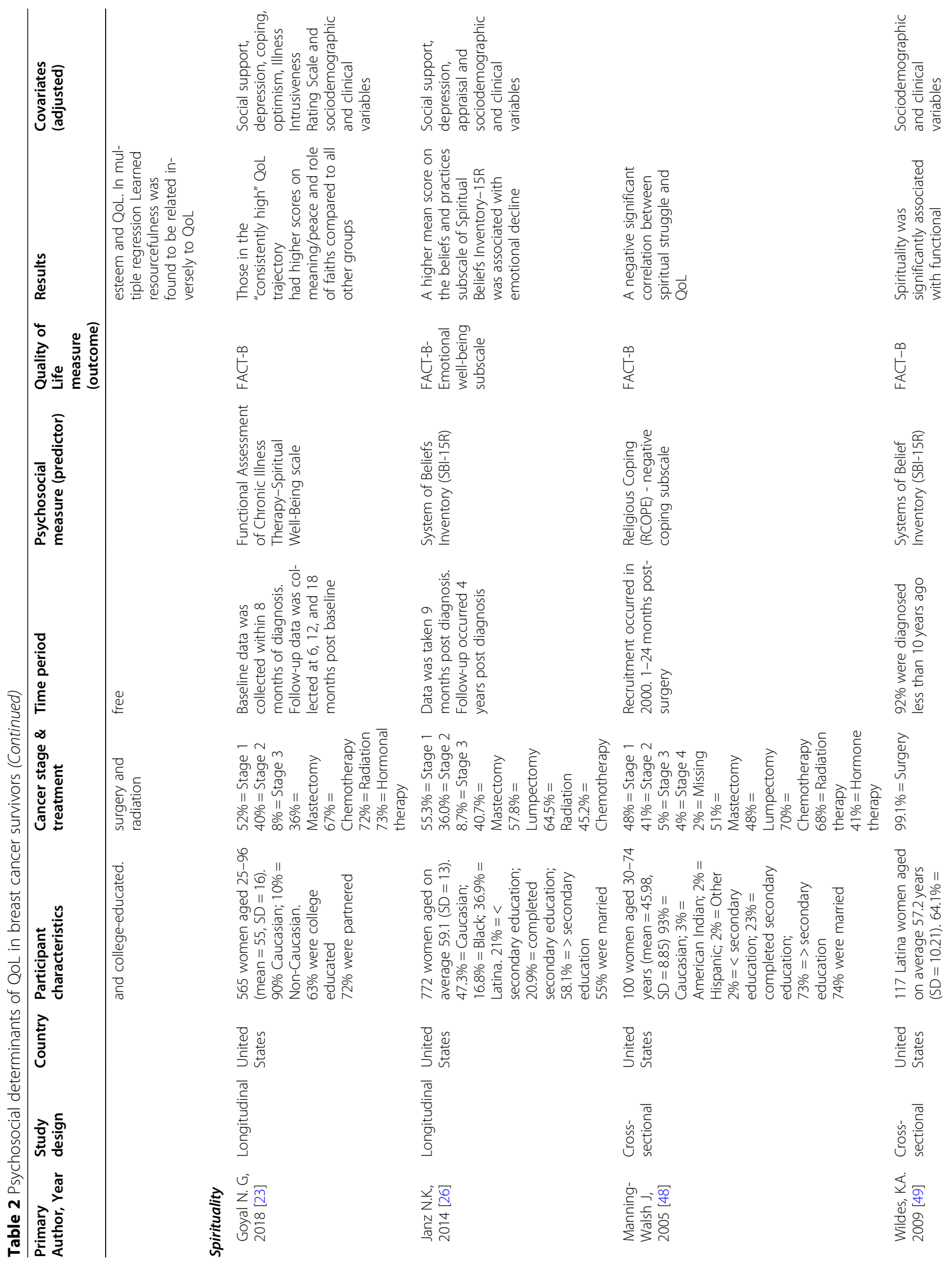




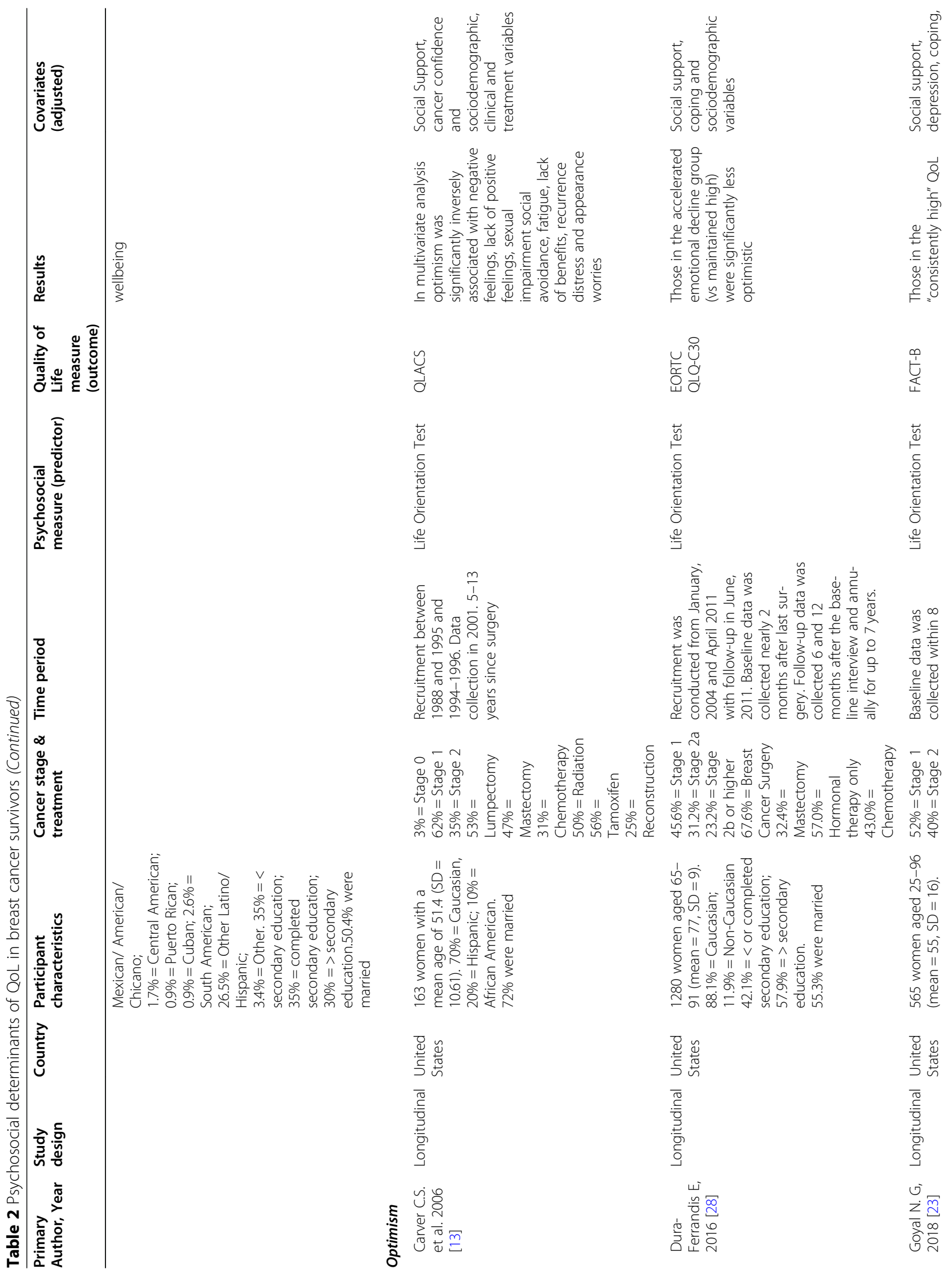




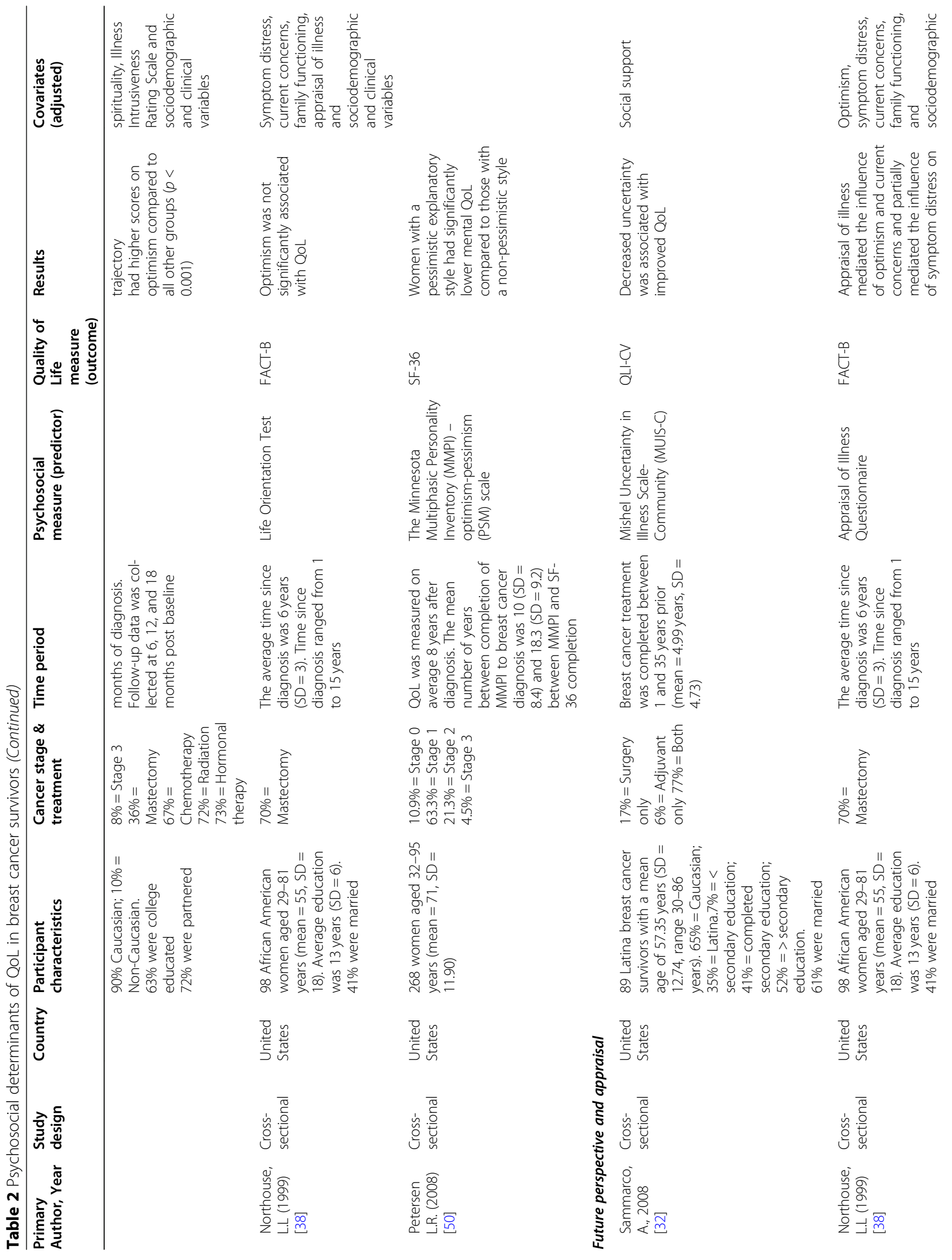




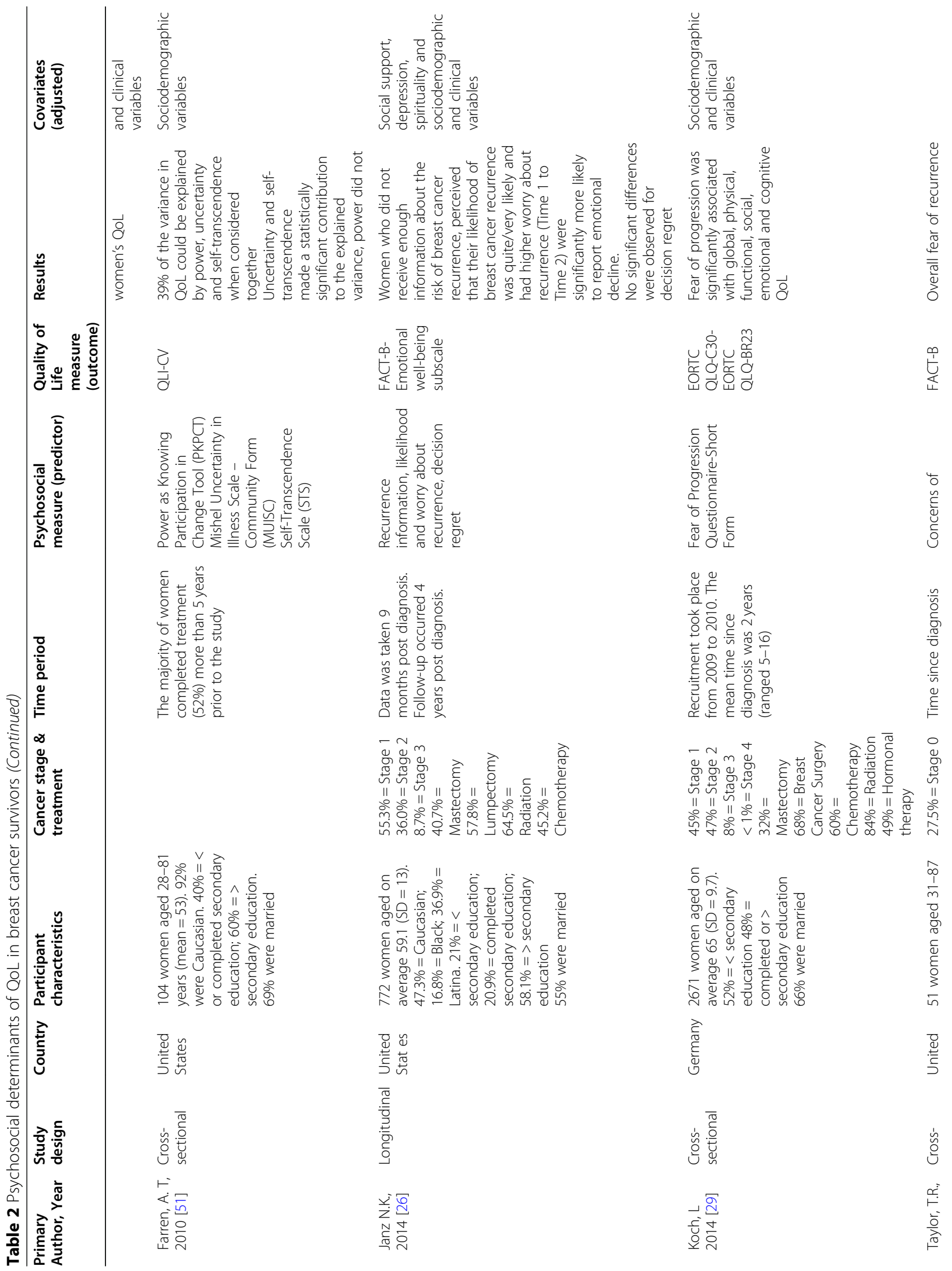




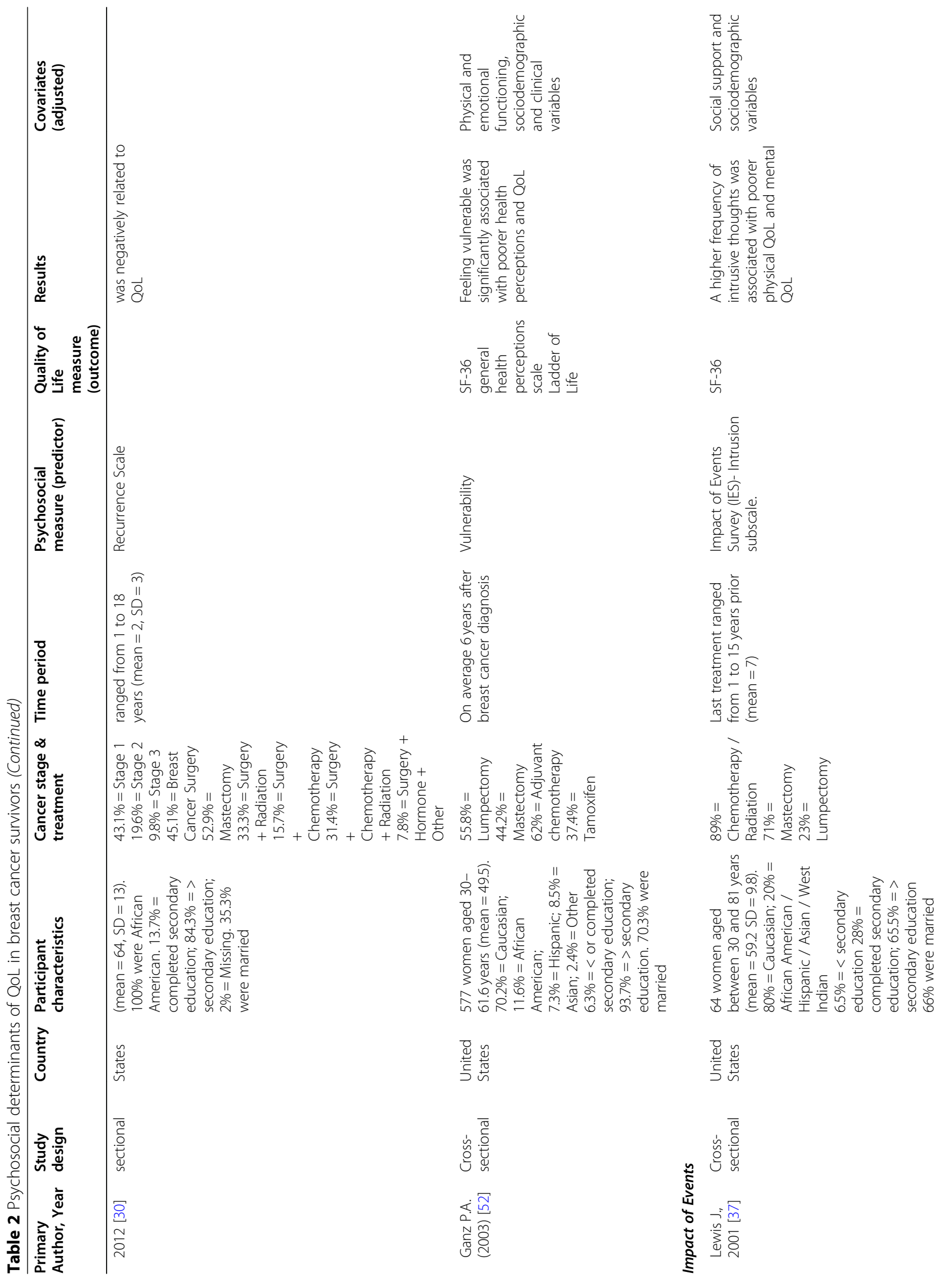









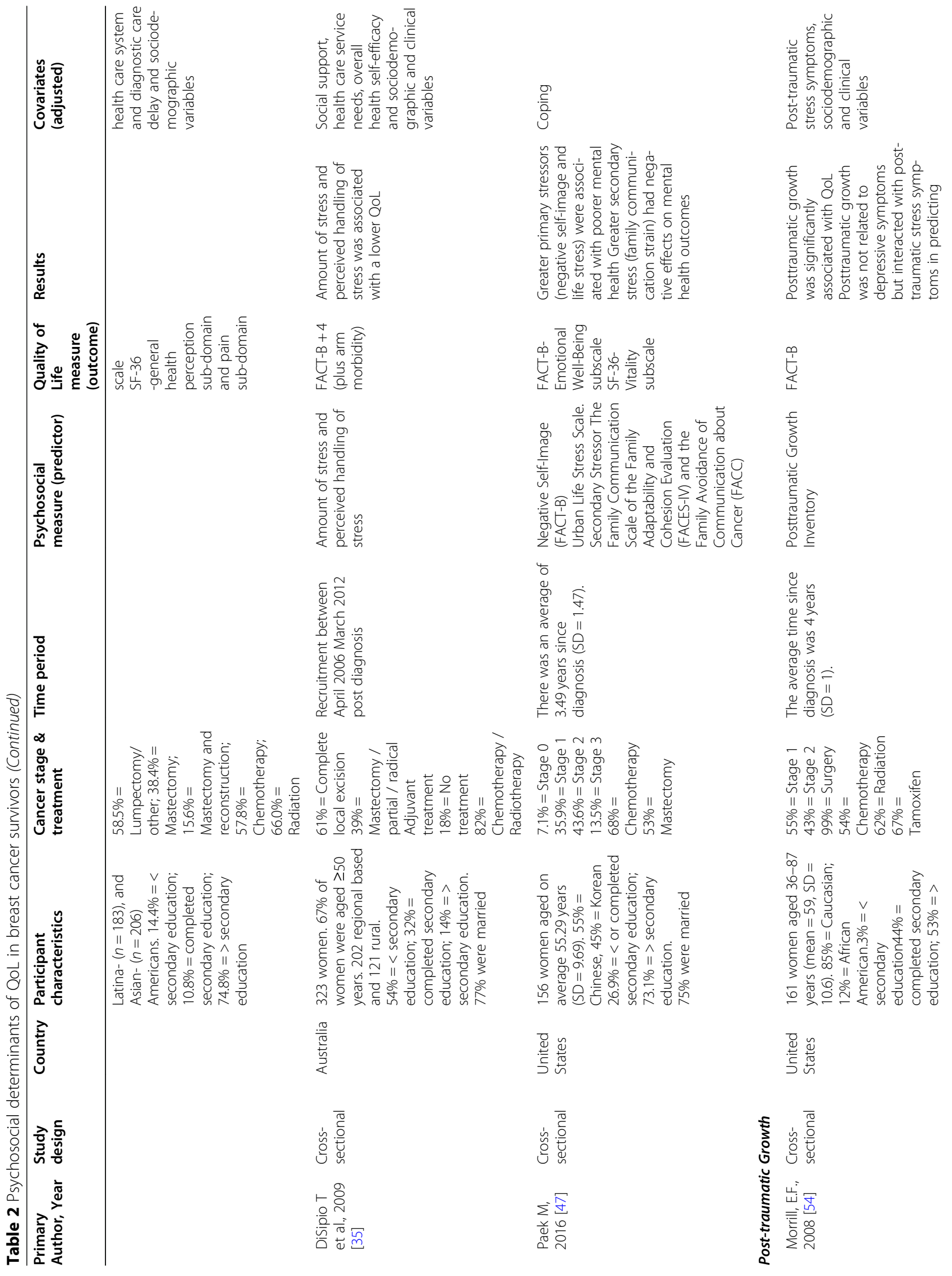




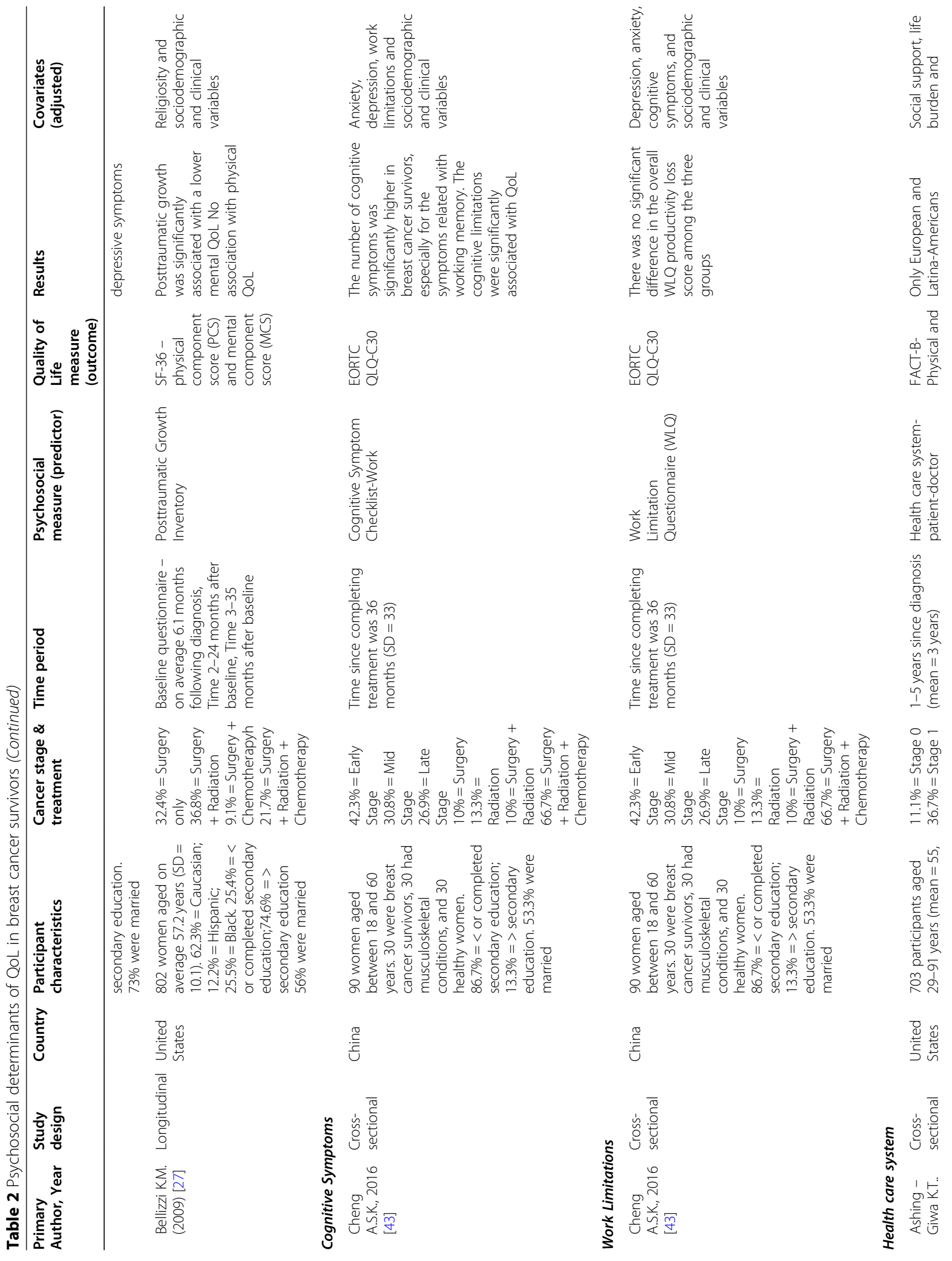




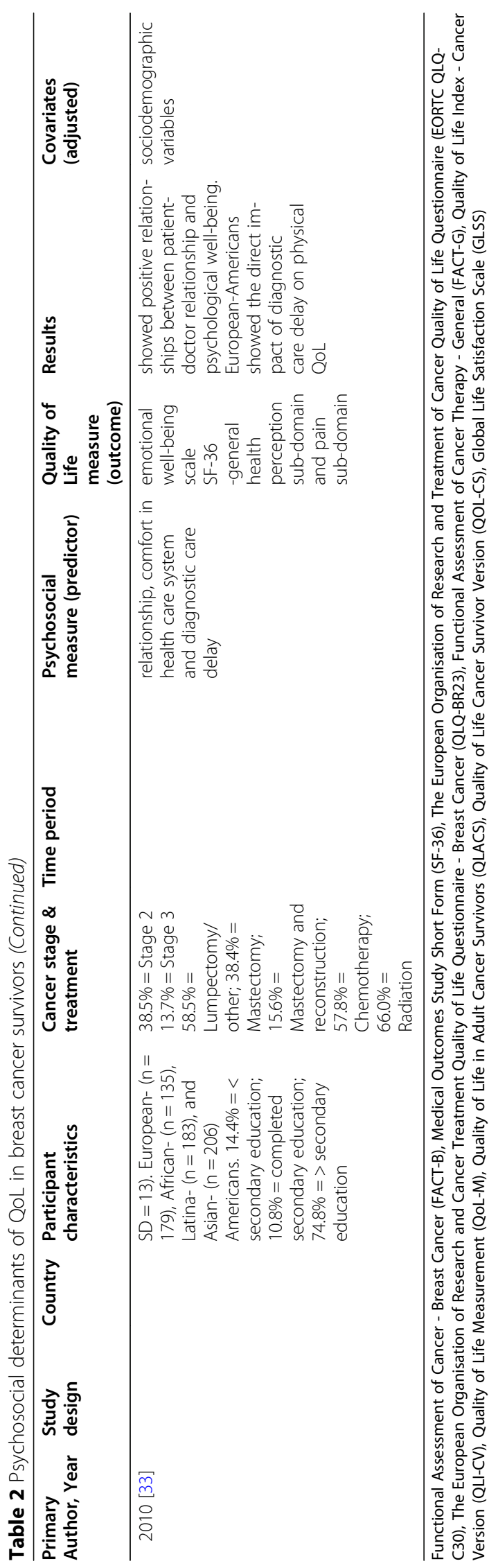


Table 3 Frequency of QoL measures

\begin{tabular}{|c|c|c|}
\hline QoL measure & $\begin{array}{l}\text { Frequency } \\
\text { used }\end{array}$ & Primary Author, Year \\
\hline $\begin{array}{l}\text { Functional Assessment of Cancer - Breast Cancer (FACT-B). This 44- } \\
\text { item self-report instrument was designed to measure multidimen- } \\
\text { sional QoL in patients with breast cancer. The FACT-B includes the } \\
\text { FACT-G with four domains covering physical, emotional, social/ } \\
\text { family and functional well-being and a Breast Cancer Subscale } \\
\text { measuring the adverse effects of endocrine therapy [21] }\end{array}$ & 13 & $\begin{array}{l}\text { Ashing-Giwa, K. T, } 2010 \text { [33], DiSipio, T., } 2009 \text { [35], Goyal, N., } 2018 \\
\text { [23], Janz, N., } 2014 \text { [26], Manning-Walsh, J., } 2005 \text { [48], Morrill, F., } \\
2008 \text { [54], Northouse, L., } 1999 \text { [38], Paek, M.S., } 2016 \text { [47], Paek, M.S., } \\
2016 \text { [25], Taylor, T., 2012 [30] Avis N.E. } 2005 \text { [41]. DeShields T } 2006 \\
\text { [24], Wildes, K., } 2009 \text { [49] }\end{array}$ \\
\hline
\end{tabular}

Medical Outcomes Study Short Form (SF-36). This questionnaire consists of an eight-item scale. The scales consist of: physical functioning, general health, vitality, social functioning, emotional, and mental health. All scales load onto one of two distinct concepts, the physical component summary or the mental component summary [55]

The European Organisation of Research and Treatment of Cancer Quality of Life Questionnaire (EORTC QLQ-C30). This questionnaire consists of 30 items incorporating nine multi-item scales: five functional scales (physical, role, cognitive, emotional, and social); three symptom scales (fatigue, pain, and nausea and vomiting); and a global health and quality-of-life scale [22]

The European Organisation of Research and Cancer Treatment Quality of Life Questionnaire - Breast Cancer (QLQ-BR23). This questionnaire consists of 23-items covering symptoms and side effects related to different treatment modalities, body image, sexuality, and future perspective [57]

Quality of Life Index - Cancer Version (QLI-CV).This 33-item questionnaire consists of four subscales: health and functioning, socioeconomic, psychological/spiritual, and family [58]

Functional Assessment of Cancer Therapy - General (FACT-G).This 27-item questionnaire has four primary QoL domains covering physical, emotional, social/family and functional well-being [21]

Ladder of Life provides a global single-item QOL score. Respondents are shown a stepladder with rungs from 1 to 10 , where 1 represents the worst possible life and 10 represents the best possible life, and asked to circle the number that represents how they feel at the present time [59]

Quality of Life Measurement (QoL-M) assesses physical, psychological, and social aspects of adaptation to breast cancer. The tool consists of 28 items placed on $10 \mathrm{~cm}$ linear analog scales to measure the perceived degree of disruption related to specific side effects and outcomes of breast cancer treatment. The items assess outcomes related to emotion regulation, problem regulation, and general QOL [46]

Quality of Life in Adult Cancer Survivors (QLACS). This 47-items questionnaire consists of 12 domains. 7 are considered generic and 5 cancer-specific. Generic domains include: physical pain, negative feelings, positive feelings, cognitive problems, sexual problems, social avoidance, and fatigue. Cancer-specific domains include financial problems resulting from cancer, distress about family, distress about recurrence, appearance concerns, and benefits of cancer [60]

Quality of Life Cancer Survivor Version (QOL-CS). This 41-items questionnaire consists of four QoL domains incorporating physical, psychological, social, and spiritual well-being [61]

Global Life Satisfaction Scale (GLSS) - adapted from the Ladder of Life - asks individuals to respond to their global life satisfaction on each of three ladders for "right now," "in 5 years," and "compared to most people". The ladder is a vertical, self-anchoring scale with 10 rungs. Scaling responses range from 0 (worst possible life) to 10 (best possible life) [59]
Lewis, J., 2001 [37], Paek, M.S., 2016 [47], Huang, C.Y., 2013 [36], Ashing-Giwa, K. T, 2010 [33], Ganz P.A., 2003 [52], Petersen, L.R., 2008 [50], Bouskill, K., 2016 [53], Bellizzi K.M., 2010 [27]

Akechi, T., 2015 [45], Cheng, A.S.K., 2016 [43], Dura-Ferrandis, E., 2016 [28], Kim, S. H.., 2008 [44], Edib Z, 2016 [56], Koch, L, 2014 [29]

Koch, L, 2014 [29], Begovic-Juhant, A., 2012 [42], Kim, S. H.., 2008 [44]

Farren, A., 2010 [51], Sammarco, A., 2008 [32], Pedro L.W.,2001 [39]

Begovic-Juhant, A., 2012 [42], Simone S.M.H., 2013 [31]

Avis N.E. 2005 [41], Ganz P.A., 2003 [52]

Kessler, T., 2002 [46]

Carver, C. S., 2006 [13]

Cheng, H., 2013 [34]

Kessler, T., $2002[46]$ 
studies [28, 29, 43-45, 56] and EORTC QLQ-BR23 in 3 studies [29, 42, 44]; with 2 of these studies using both the EORTC QLQ-C30 and QLQ-BR23 [29, 44]. Three studies applied the Quality of Life Index Cancer Version (QLI-CV) [32, 39, 51]. The remaining QoL measures were used less frequently ( $\leq 2$ studies). Seven studies (21\%) used more than one measure of QoL as an outcome [29, 33, 41, 42, 44, 47, 52].

\section{Frequency of psychosocial determinants measurement tools per individual QoL measures in breast cancer survivors}

A range of different measurement tools were used per psychosocial determinant (Table 4). There were 10 different measures of social support used in 14 studies, with the Medical Outcomes Survey (MOS) Social Support Survey and the Interpersonal Support Evaluation List (ISEL) used most frequently (3 studies respectively). The majority of measurement tools were used in only 1 or 2 studies. Table 5 presents the frequency of the individual psychosocial determinant measures per individual QoL measure. The 14 studies that measured the influence of the determinant social support employed 10 different measures of social support and 7 different measures of QoL. The MOS Social Support Survey was used to measure social support in 3 different studies but only 2 of these studies used the same QoL measure [23, 33]. Similarly depression was measured by 4 different measures and its influence was assessed using 4 different QoL measures. While future appraisal and perspective was measured in 7 studies using 8 different measures and 6 different QoL measures; only 2 studies used the same measure for the determinant (uncertainty in illness) and QoL [32, 51].

\section{Assessing the influence of the psychosocial determinants on QoL in breast cancer survivors}

Among the studies that investigated social support, the general conclusion was that low perceived support was associated with a worse QoL [35, 41, 56] and higher levels of support were associated with better QoL [13, $23,28,32,34,37,38]$. Three studies found that the influence of social support on QoL varied by the type of support e.g. appraisal, belonging [36, 39]. Only 2 studies found no association between social support and QoL $[26,33]$.

For depression, 6 studies showed an inverse relationship with higher/lower levels of depression associated with a lower/higher QoL [23, 24, 26, 31, 42, 44] and one study found no association [43]. Out of the 7 studies that investigated future appraisal and perspectives, fear/ worry about cancer recurrence was associated with a lower QoL in 4 studies [26, 29, 30, 52]. Higher uncertainty about illness was found to be associated with a lower Qol in 2 studies [32, 51] and appraisal of illness was also shown to mediate the influence of concerns and optimism on women's QoL in one study [38].

The 5 studies that looked into coping generally found that the most relevant aspect of coping was the type of coping strategy one used, with disengagement, selfdistraction, keeping to self and wishful thinking all having a negative association with QoL $[28,41,47]$. In general higher utilisation of active coping and lower utilisation of passive coping were positively associated with QoL $[23,25,41]$. Four of the 5 studies that assessed the role of optimism on QoL found that higher levels of optimism were positively associated with QoL $[13,23$, 28, 50]; the remaining study was null [38]. All 5 studies that investigated stress found that greater psychological stress, symptom distress and life burden were associated with a lower QoL [33, 35, 38, 47, 54].

The 4 studies that examined the association between faith or spirituality and QoL had mixed findings. One study found that women with greater spiritual beliefs were more likely to have a lower emotional QoL [26], and another study reported that spiritual struggles were associated with lower QoL [48]. The other 2 studies concluded that higher rates of engagement with faith and spirituality had a positive impact on QoL $[23,49]$.

For the 3 studies that assessed anxiety, 2 studies reported that higher anxiety was associated with a lower QoL $[31,45]$ while the remaining study found a null association [43]. In 3 individual studies higher confidence, self-efficacy and self-esteem were each found to be associated with higher QoL $[13,35,39]$. Higher frequency of intrusive thoughts in 2 studies [23, 37] and a perceived negative impact of cancer in 1 study were associated with a lower QoL [53].

Two studies found that higher scores for posttraumatic growth were associated with a higher QoL [27, 54]. While higher scores on negative affect and cognitive limitations were found to be associated with a lower QoL $[43,46]$. Work limitations were reported to have no significant impact on QoL [43]. The one study on health care system determinants found that a positive patientdoctor relationship was associated with better psychological well-being, while diagnostic care delay was associated with lower physical well-being in some ethnic groups [33].

\section{Discussion}

This review confirms that there are numerous psychosocial determinants that are associated with QoL in breast cancer survivors. The psychosocial determinants investigated most frequently were social support, depression and future appraisal and perspective. There was less research undertaken on societal determinants, such as healthcare system factors, work limitations etc. In 
Table 4 Description and frequency of psychosocial measures

Psychosocial measure \begin{tabular}{ll}
$\begin{array}{l}\text { Frequency Primary Author, Year } \\
\text { used }\end{array}$ & \\
\hline
\end{tabular}

\section{Social Support}

Medical Outcomes Study (MOS) Social Support Survey-(19 items)- measures perceived availability of support: emotional/informational support, tangible support, affectionate support, and positive social interaction [62]

Interpersonal Support Evaluation List (ISEL)- 40 items- evaluates the perceived availability of four dimensions of social support consisting of belonging, appraisal, tangible and self-esteem support. Belonging support is the availability of people with whom one can do things. Appraisal support is the availability to talk to or behaviours of a supporting person, including empathy, caring, love and trust. Tangible support is instrumental aid and comprises providing support in a physical way that assists an individual in meeting their role responsibilities. Self-esteem support is the availability of a positive comparison when comparing oneself with others [63]

Social Support Questionnaire (SSQ-6) -6 questions asking about the affective aspects of social support. Each question has two parts, which are the number of support persons (SSQ6-N) and the satisfaction with social support (SSQ6-S) [64].

Social Networks Index - assesses participation in 12 types of social relationships. These include relationships with a spouse, parents, parents-inlaw, children, other close family members, close neighbours, friends, workmates, schoolmates, fellow volunteers, members of groups without religious affiliation, and religious groups. One point is assigned for each type of relationship (possible score of 12) for which respondents indicate that they speak (in person or on the phone) to persons in that relationship at least once every 2 weeks [65].

Emotional support from health care providers, family members and friends/ co-workers (rated low vs. high). Satisfaction with partner scale was combined with marital status as follows: (1) respondent did not report a partner; (2) respondent is slightly satisfied or very satisfied with partner relationship, or (3) respondent is neutral, slightly, or very unsatisfied with their partner

Social Support Questionnaire (SSQ-8) is a self-administered measure of social 1 support from five sources: spouse, family member, friend, nurse, and physician (40 items in all) [66].

Family APGAR-family functioning- a 5-item scale assesses participants' satisfaction with their family's ability to communicate, assist one another, and respond to change. Each item (e.g., "I am satisfied when I can turn to my family for help when something is troubling $\mathrm{me}^{\prime \prime}$ ) is rated on a scale from 1 (never) to 5 (always) [67].

Norbeck Social Support Questionnaire (NSSQ) is a self-administered 9-item in- 1 strument that measures the multiple dimensions of social support including functional components of affirmation, aid, and affection; social network properties of frequency of contact, number in network, and duration of relationships; and recent losses of supportive relationships [68]

Supportive Care Needs Survey- Short Form- is a standardised instrument for measuring cancer patients' perceived needs across a range of domains. A total number of 34-items are divided into five domains: physical/daily living (5 items), psychological (10 items), sexuality (3 items), patient care and support (5 items) and health system and information needs (10 items) [69]. Supportive Care Needs Survey - Health system and information needs domain only [69].

Cancer Rehabilitation Evaluation System (CARES)- a multidimensional selfadministered instrument containing multiple problem areas. Administered the marital and sexual scales and the body image subscale. The marital scale includes five subscales (communication with partner, affection with partner, interaction with partner, neglect by partner and overprotection). The sexual scale included two subscales: sexual interest and sexual dysfunction [70].

\section{Depression}

Centre for Epidemiological Studies-Depression (CES-D) is a screening tool for 2 depressive symptoms and includes 20-item to investigate perceived mood and level of functioning within the past 7 days. Scores of 16 or higher are considered indicative of depression [71].
Ashing -Giwa K.T.. 2010 [33], Dura-Ferrandis E, 2016 [28], Goyal N. G, 2018 [23]

Carver C.S. 2006 [13], Huang C.Y. 2013 [36] Lewis, J., $2001[37]$

Cheng H, 2013 [34]

DiSipio T, 2009 [35]

Janz N.K., 2014 [26]

Sammarco, A., 2008 [32]

Northouse, L.L (1999) [38]

Pedro L.W. (2001) [39]

Edib Z (2016) [40]

DiSipio T., 2009 [35]

Avis N.E. (2005) [41] 
Table 4 Description and frequency of psychosocial measures (Continued)

\section{Psychosocial measure \\ Hospital Anxiety and Depression Scale (HADS) is a validated screening instrument for anxiety and depression in somatically ill patients. A score of 0 to 7 is categorized as normal, a score of 8 to 10 is considered to indicate a possible anxiety or depressive disorder, and a score of 11 or above is considered to indicate a probable anxiety or depressive disorder [72]. \\ Becks Depression Inventory- a 21-item, self-report rating inventory that mea- sures characteristic attitudes and symptoms of depression [74]. \\ Depression history -no history, history of depression without current symptoms, history of depression with current symptoms \\ Anxiety \\ Hospital Anxiety and Depression Scale (HADS) is a validated screening instrument for anxiety and depression in somatically ill patients. A score of 0 to 7 is categorized as normal, a score of 8 to 10 is considered to indicate a possible anxiety or depressive disorder, and a score of 11 or above is considered to indicate a probable anxiety or depressive disorder [72].}

\section{Positive and negative affect}

Positive and Negative Affect Scale (PANAS) is a 20-item tool that contains two 10-item scales, one measuring positive affect and the other negative affect. Positive affect items reflect the extent to which an individual feels enthusiastic, active, and alert. Negative affect items reflect subjective feelings of distress, including anger, contempt, guilt, fear, and nervousness [75].

\section{Coping}

Brief COPE- 9 of the original 14 subscales were grouped. Active coping, instrumental support, emotional support, acceptance, and positive reframing were combined to assess Engagement Coping. The behavioral disengagement and denial subscales were combined as Disengagement Coping. Venting and self-distraction were considered as separate subscales [76].

Brief COPE- The 28-item scale was used to measure 14 types of coping strat- 2 coping, use of emotional support, use of instrumental support, and positive reframing) and passive coping (self-blame, denial, and behavioral disengagement) [76].

Family Crisis Oriented Personal Evaluation Scale (F-COPES)- assesses a family's 1 problem-solving strategies in response to family problems/difficulties and includes 3 external (use of outside resources) and 2 internal family coping strategies (utilize the family's internal strengths/resources). This study focused on the following coping: external (6-item acquiring social support from friends/relatives, 3-item acquiring social support from neighbors, and 4-item seeking spiritual support) and internal (8-item reframing) family coping strategies [77].

Ways of Coping-Cancer Version - participants were asked to indicate how often they had used each of the following strategies in the last 6 months in attempting to cope with the most stressful part of their breast cancer; seeking and using social support, keeping feelings to self, using positive cognitive restructuring, using wishful thinking, making changes, spirituality and detachment. Three items assessed feelings of preparedness for coping with breast cancer, how well prepared patients were for the impact of cancer on their relationships, how they might feel about their appearance after surgery, and availability of counseling or support groups [78].

\section{Confidence and self-efficacy}

Question- confidence about remaining cancer free- To what extent do you believe that you will remain free of cancer in the future?' answered on a nine-point scale, with $9=$ absolutely sure I won't get cancer again, $5=1$ don't know and 1 = not at all confident, I expect to get cancer again

The Self Rated Abilities for Health Practices Scale (SRAHP) is a 28-item, 5 point scale to measure self-perceived ability to implement health-promoting behaviors. SRAHP contains four subscales: Exercise, Nutrition, Responsible

\section{Frequency Primary Author, Year}

used

2

Cheng A.S.K., 2016 [43], Simone, S.M. H, 2013 [73]

Goyal N. G, 2018 [23], Kim, S.H.., 2008 [44]

Janz N.K., 2014 [26]

Akechi, T., 2015 [45], Cheng A.S.K., 2016 [43], Simone, S.M. H, 2013 [73]

Kessler, T. A. 2002 [46]

Dura-Ferrandis E, 2016 [28]

Goyal N. G, 2018 [23], Paek, M., 2016 [25]

Paek M, 2016 [47]

Avis N.E. (2005) [41] 
Table 4 Description and frequency of psychosocial measures (Continued)

\section{Psychosocial measure Frequency Primary Author, Year \\ used}

Health Practice, and Psychological Well Being. Each subscale has seven items. Respondents are asked to rate the extent to which they are able to perform health practices related to these four domains [79].

Rosenberg Self-Esteem Scale- a self-administered, 10-item scale that measures the self-acceptance aspect of self-esteem or the overall sense of being capable, worthwhile, and competent [80].

Rosenbaum Self-Control Schedule- used as a measure of learned resourceful- 1 ness (36 items). For each of the 36 items participants indicate the degree to which it describes their behavior on a 6-point scale ranging from extremely descriptive $(+3)$ to extremely non-descriptive $(-3)$ [81].

\section{Spirituality}

Functional Assessment of Chronic Illness Therapy - Spiritual Well-Being (FACl 1 T-SP-12). This 12-item questionnaire consists of two subscales, one measuring a sense of meaning and peace and the other assessing the role of faith in illness [82].

Religious Coping (RCOPE) - spiritual struggle was measured using the 7-item 1 Negative Coping subscale of RCOPE. Examples of items on the Negative Coping subscale include "I wondered what I did for God to punish me" and "I wondered whether God had abandoned me". Measured on a 4-point Likert-type scale ranging from 0 (not at all) to 3 (a great deal), the participants were asked to indicate the degree to which they used each strategy [83].

System of Beliefs Inventory- (SBI-15R) - which measures both religious and spiritual aspects of belief systems in coping with a life-threatening illness. The SBI-15R encompasses both constructs by assessing beliefs and practices of faith systems (10 items, Subscale I) and social support from the religious and/or spiritual community (5 items, Subscale II), and applies equally to atheists, agnostics, those with no religious affiliation, and those with a moderate or strong religious or spiritual orientation [84].

The SBI-15R was modified to include 4 items from the Beliefs and Practices subscale (e.g. "Religion is important in my day-to-day life", "Prayer has helped me cope during times of serious illness") and four items from the Social Support subscale (e.g., "I enjoy attending religious functions held by my religious or spiritual group", "I know someone in my religious or spiritual community that I can turn to"). Items from each subscale were averaged for all participants, with a range of values from 1 (strongly disagree) to 5 (strongly agree) [84].

\section{Optimism}

Life Orientation Test-comprised of 8 items, plus 4 filler items that are not calculated in the total score. Each item (e.g., "I always look on the bright side of things"), is rated on scale from 0 (strongly disagree) to 4 (strongly agree). Individual items are summed (excluding the filler items) with higher scores indicating more dispositional optimism [85].

The Minnesota Multiphasic Personality Inventory (MMPI) - The original MMPI 1 is a 566-item self-report inventory that utilizes a true/false response format. The MMPI yields information about personality factors related to psychiatric syndromes. The optimism-pessimism (PSM) scale was developed using 298 MMPI items [86].

\section{Future perspectives and appraisal}

Mishel Uncertainty in Illness Scale - Community Form (MUISC) is a 23-item, 5-point (strongly disagree to strongly agree), Likert-type scale, selfadministered measure of the uncertainty perceived in illness [87].

Appraisal of illness scale- consists of 27 scored items (e.g., "this situation threatens to overwhelm me") and 5 unscored filler items, with a 5-point Likert-type response format with choices ranging from 1 (very false) to 5 (very true) [88].

Power as Knowing Participation in Change Tool (PKPCT) is a 52 item semantic differential scale designed to measure an individual's capacity to participate knowingly in change on four subscales (awareness, choices, freedom to act intentionally, and involvement in creating change) [89].
Pedro L.W. (2001) [39]

Pedro L.W. (2001) [39]

Goyal N. G, 2018 [23]

Manning-Walsh J, 2005 [48]

Wildes, K.A. 2009 [49]

Janz N.K., 2014 [26]

Carver C.S. et al. 2006 [13], Dura-Ferrandis E, 2016 [28] Goyal N. G, 2018 [23], Northouse, L.L (1999) [38]

Petersen L.R. (2008) [50]

Sammarco, A., 2008 [32], Farren, A. T, 2010 [51]

Northouse, L.L (1999) [38]

Farren, A. T, 2010 [51] 
Table 4 Description and frequency of psychosocial measures (Continued)

\begin{tabular}{ll}
\hline Psychosocial measure & $\begin{array}{l}\text { Frequency Primary Author, Year } \\
\text { used }\end{array}$
\end{tabular}

Self-Transcendence Scale (STS) measures the capacity for self-transcendence. 1

It is a unidimensional, 15-item, 4-point Likert scale. The scale ranges from not at all to very much [90].

Received enough information from their doctors or the staff about risk of breast cancer recurrence (yes/no). (Time 1)

Perceived likelihood of breast cancer recurrence ("not at all likely" to "very likely to recur"). (Time 2)

Worry about recurrence-concern the cancer would recur in the same breast, the other breast, or to another part of the body. (Change from Time 1 to Time 2 scores

Decision regret -categorized as a lot of decision regret versus none or some decision regret [91].

Fear of Progression Questionnaire-Short Form- (FoP-Q-SF) consists of 12 pation, and loss of autonomy), answered on a Likert scale (frequency of experience of fear/worry: $1=$ never to $5=$ very often) [92].

Concerns of Recurrence Scale (CARS) assesses the extent and the nature of women's concerns about breast cancer recurrence. Two components; Overall fear index includes 4 questions on frequency, potential for upset, consistency, and intensity of fears. Scores are given on a six-point Likert scale that ranges from 1 (not at all) to 6 (continuously). The nature of women's fears about recurrence includes 26 items subdivided into four domains: health worries, womanhood worries, role worries, and death worries. Health worries (11 items) measures concern about future treatment (e.g., chemotherapy, radiation, and surgery), emotional upset, physical health, carrying out planned activities, and loss of breast(s). Womanhood worries (7 items) measure femininity, sexuality, womanhood, body image, romantic relationships, identity, and spirituality or faith. Role worries (6 items) measure roles and responsibilities at work and at home, relationships with friends and family, physical ability to complete daily activities, financial problems, and self-confidence. Death worries ( 2 items) measure the possibility that a recurrence of breast cancer could lead to death. Scores range from 0 (not at all), 1 (a little), 2 (moderately), 3 (a lot), to 4 (extremely), to indicate the extent to which they worry about each item [93].

Perceptions of life- a 12-item scale to measure perceptions of life after cancer 1 (developed by the authors). Example items include "Surviving breast cancer has changed my outlook on life,", "I get less worried about trivial things," and "I feel more vulnerable now, as if the world is a more dangerous place." Respondents indicate the extent to which they believe their outlook has changed on a 5-point scale, ranging from 0 (not at all) to 4 (very much). The first factor includes six items assessing changes in perspectives and priorities as a measure of positive meaning. The second factor includes five items assessing fears about recurrence and about one's body, and measures vulnerability [94].

\section{Impact of Events}

Impact of Events Survey (IES)- The IES is a 15 item self-report measure of intrusive thoughts and avoidance associated with a stressor (breast cancer). In this study the Intrusion subscale of the IES is considered a measure of processing. Participants rated how true each statement has been for them in the past 3 weeks, using the following scale: $0=$ Not at all, $1=$ Rarely, $3=$ Sometimes, and $5=$ Often. All statements were anchored to the participant's cancer and its treatment, such as "Thought about it when I didn't mean to" and "I had dreams about it." [95]

Illness Intrusiveness Rating Scale- measures the impact of cancer on multiple 1 life areas (13-items). Using a Likert scale ranging from one (not very much) to seven (very much), participants rate the degree of interference caused by their illness or its treatment with 13 aspects of their lives. These domains are: health, diet, work, active and passive recreation, financial situation, relationship with spouse, sex life, family and other social relations, selfexpression/self-improvement, religious expression and community/civic involvement [96].

Impact of Cancer scale-is a self-report instrument that is designed to capture 1 how long-term survivors interpret the overall positive and negative impacts 
Table 4 Description and frequency of psychosocial measures (Continued)

\section{Psychosocial measure \\ of having cancer in their lives. Item responses are in a five-point Likert scale format where respondents are asked to give their overall agreement from 1 (strongly disagree) to 5 (strongly agree). Mean scores are compiled for each domain and then aggregated into the two meta-domains: the positive im- pact of cancer (PIC) and the negative impact of cancer (NIC) [97].}

\section{Stress}

Post-traumatic Stress Disorder Checklist Civilian Version (PCL-C) -assesses post-traumatic stress symptoms. The PCL-C is a 17-item self-report checklist of PTSD symptoms based closely on the DSM-IV criteria. Respondents rate each item from 1 ("not at all") to 5 ("extremely") to indicate the degree to which they have been bothered by that particular symptom over the past month [98].

Omega Screening Questionnaire (OSQ) - is comprised of four parts: (a) demographic and background information, (b) health history, (c) inventory of current concerns, and $(d)$ symptoms scale. The demographic section of the OSQ includes a number of questions about the respondent's age, education, income, and so forth. The Inventory of Current Concerns is a 40-item scale that asks participants to rate the extent to which they have experienced a list of concerns about issues such as finances, children and work in the past month. Participants rate each item according to whether the statement is not true (0), somewhat true (1), or true (2) for them. The Symptoms Scale asks participants to rate the extent to which they have experienced 13 symptoms (e.g., fatigue, breathing problems, pain). Response options are 0 (no trouble), 1 (some), and 2 (a lot) [99].

Life Stress Scale - Life burden- which assesses the level of stress associated with various aspects of daily living. Scale consists of family (6-items), functional (4-items), and neighborhood stresses (6-items), Items are rated from 1 to 5, with a higher score indicating less life burden/ stress, and calculated into a mean score [100].

Amount of stress (very little, some, a moderate amount, a lot) Perceived handling of stress (not well at all, not well, fairly well, very well)

FACT-B Additional Concerns subscale.

Negative self-image was measured using two items (e.g. "I feel sexually attractive" and "I am able to feel like a woman") [21]

Urban Life Stress Scale assesses the level of life-related stress for the past 3month [101]. In this study, a three-factor structure was selected and named as "functional stress" (e.g., finances, job situation; 3-item), "stressful life-events" (e.g., illness of someone close; 2-item), and "role stress" (e.g., parenting; 3item).

The Family Communication Scale of the Family Adaptability and Cohesion Evaluation (FACES-IV) [102] and the Family Avoidance of Communication about Cancer (FACC) Scales [103] were used to assess both general and cancer-specific family communication problems. A composite score was created by averaging the $z$ scores of both measures, with greater scores representing higher communication strain.

\section{Posttraumatic Growth}

Posttraumatic Growth Inventory-an instrument for assessing positive outcomes reported by persons who have experienced traumatic events. This 21item scale includes factors of New Possibilities, Relating to Others, Personal Strength, Spiritual Change, and Appreciation of Life [104]

\section{Cognitive Symptoms}

Cognitive Symptoms Checklist-Work-21 items are used to assess work-related 1 cognitive problems. The original English version consists of three subscales, including working memory, executive functioning, and attention. The Chinese version used by this current study applied a two-factor instead of threefactor structure that combined items measuring task completion and executive function [105].

\section{Work Limitations}

\section{Frequency Primary Author, Year}

used

Morrill, E.F., 2008 [54]

Northouse, L.L (1999) [38]

Ashing -Giwa K.T.. 2010 [33]

DiSipio T et al., 2009 [35]

Paek M, 2016 [47]

Paek M, 2016 [47]

Paek M, 2016 [47] 
Table 4 Description and frequency of psychosocial measures (Continued)

\begin{tabular}{|c|c|c|}
\hline Psychosocial measure & $\begin{array}{l}\text { Frequency } \\
\text { used }\end{array}$ & Primary Author, Year \\
\hline \multicolumn{3}{|c|}{$\begin{array}{l}\text { limitation, which is inversely related to work productivity. The } 25 \text {-item WLQ } \\
\text { consists of four subscales: time demands, physical demands, mental interper- } \\
\text { sonal demands, and output demands; and users rate their ability or level of } \\
\text { difficulty in fulfilling the job demands on a scale ranging from } 1 \text { to } 5 \text { [106]. }\end{array}$} \\
\hline \multicolumn{3}{|l|}{ Healthcare System } \\
\hline $\begin{array}{l}\text { Health care system- patient-doctor relationship ( } 6 \text { items), comfort in health } \\
\text { care system ( } 3 \text { items) and diagnostic care delay ( } 1 \text { item). Patient-doctor rela- } \\
\text { tionship was assessed from the Interpersonal Aspects of Care subscale of the } \\
\text { Adherence Determinants Questionnaire. This measure focuses on interper- } \\
\text { sonal aspects of care, communication, and rapport on a scale from } 1 \\
\text { (strongly disagree) to } 5 \text { (strongly agree). (113) Comfort in health care system } \\
\text { included use of regular medical check-ups, comfort using the health care } \\
\text { system, and comfort in asking questions. Each score was standardized ran- } \\
\text { ging from } 0 \text { to } 100 \text { and averaged to obtain an overall score. Diagnostic care } \\
\text { delay was assessed by asking respondents how long (number of days) they } \\
\text { waited to obtain medical care from the time they first noticed something } \\
\text { was wrong. It was calculated by the time interval (days) between the first } \\
\text { symptom and medical diagnosis }\end{array}$ & 1 & Ashing -Giwa K.T.. 2010 [33] \\
\hline
\end{tabular}

general, across all the 33 articles included in this review, a higher level of a positive influence and a lower level of a negative influence of a psychosocial determinant was associated with a better QoL e.g. higher social support and lower levels of depression were found to be associated with a higher/better QoL. There were some determinants such as spirituality and coping were the influence on QoL was mixed or it varied, depending on which aspect of the determinant was measured e.g. type of coping strategy; but these determinants were also less commonly investigated.

This review also identified a range of gaps and limitations in the current literature and areas for further research. The majority of studies were cross-sectional and assessed the influence of psychosocial determinants on QoL at a single point in time. It is possible that the influence of psychosocial determinants on QoL may vary over time. A US study of breast cancer survivors found that when worry about recurrence increased over time (4 years after diagnosis), women were more likely to report a decline in emotional well-being. On average, there was a gradual lessening of worry as the years of survivorship increased, but some women reported greater worry at 4 years than they did shortly after primary treatment was completed [26]. The majority of the studies were undertaken in North America and the findings may not be transferable to other countries, with differing health care systems and cultures.

There is also considerable variation in the type of measures being used to assess both QoL and the individual psychosocial determinants across studies. There were 12 different QoL measures utilised across the 33 studies. Some of the QoL measures were breast cancer specific (FACT-B), some were cancer focussed (though not specific to a particular cancer; EORTC QLQ-C30) and some were generic (SF36) and hence may not have focussed on the same aspects of QoL aspects. Thus findings may not be comparable. A systematic review of QoL instruments in long-term breast cancer survivors identified only three instruments (QLACS, QLI-CV, QOL-CS) that evaluated all four domains of QoL (physical, psychological, social and spiritual) [107]. These instruments were only used in 5 studies in the current review (Table 3). Similarly, this review identified that on average 6 different measures were used per psychosocial determinant, making comparability of findings difficult.

While the findings provide evidence of a relationship between individual psychosocial determinants and QoL, they are not conclusive. Across the 34 studies there was only ever a maximum of 2 studies where results could be directly compared and this was only feasible for 6 determinants; social support, anxiety, coping, spirituality, optimism and future perspectives and appraisal. (Table 5) The clinical relevance of the possible effects of the determinants on QoL is also difficult to interpret. Differences in QoL should be compared to the minimal important difference for the various QoL measures, if known e.g. estimated to be in the range of 3-8 points for the FACT-B [108, 109]. It is also possible given the breadth in definition of a "psychosocial determinant", that there are a range of other determinants whose influence on QoL has yet to be measured in studies e.g. motivation, goals. A recent systematic review identified that cancer may impact patients' life goals and life goal disturbance may be related to poorer psychological outcomes but further studies are required [110].

This is the first scoping review of the psychosocial determinants of QoL in breast cancer survivors. 
Table 5 Frequency of psychosocial determinant measures per individual QoL measure

\begin{tabular}{|c|c|c|c|c|c|c|c|c|c|c|}
\hline & $\begin{array}{l}\text { FACT- } \\
\text { B }\end{array}$ & SF-36 & $\begin{array}{l}\text { EORTC } \\
\text { QLQ- } \\
\text { C30 }\end{array}$ & $\begin{array}{l}\text { EORTC } \\
\text { QLQ- } \\
\text { BR23 }\end{array}$ & $\begin{array}{l}\text { FACT- } \\
\text { G }\end{array}$ & QLI-CV & $\begin{array}{l}\text { Ladder } \\
\text { of Life }\end{array}$ & QOLM & $\begin{array}{l}\text { QLAC } \\
\mathrm{S}\end{array}$ & $\begin{array}{l}\text { QOL- } \\
\text { CS }\end{array}$ \\
\hline \multicolumn{11}{|l|}{ Social Support } \\
\hline $\begin{array}{l}\text { Medical Outcomes Study (MOS) Social Support } \\
\text { Survey- } 3 \text { items }\end{array}$ & $\begin{array}{l}2[23, \\
33]\end{array}$ & $1[33]$ & $1[28]$ & & & & & & & \\
\hline Interpersonal Support Evaluation List (ISEL) & & $2[36,37]$ & & & & & & & $1[13]$ & \\
\hline Social Support Questionnaire (SSQ)- 6 items & & & & & & & & & & $1[34]$ \\
\hline Social Support Questionnaire (SSQ)- 8 items & & & & & & $1[32]$ & & & & \\
\hline Norbeck Social Support Questionnaire- 9 items & & & & & & $1[39]$ & & & & \\
\hline Social Networks Index & $1[35]$ & & & & & & & & & \\
\hline Supportive Care Needs Survey & $1[35]$ & & $1[56]$ & & & & & & & \\
\hline Cancer Rehabilitation Evaluation System (CARES) & $1[41]$ & & & & & & $1[41]$ & & & \\
\hline $\begin{array}{l}\text { Emotional support from others and satisfaction with } \\
\text { partner scale }\end{array}$ & $1[26]$ & & & & & & & & & \\
\hline Family APGAR-family functioning & $1[38]$ & & & & & & & & & \\
\hline \multicolumn{11}{|l|}{ Depression } \\
\hline $\begin{array}{l}\text { Center of Epidemiologic Studies Depression Scale } \\
\text { (CES-D) }\end{array}$ & $1[24]$ & & & $1[42]$ & $1[42]$ & & & & & \\
\hline Hospital Anxiety and Depression Scale (HADS) & & & $1[43]$ & & $1[73]$ & & & & & \\
\hline Becks Depression Inventory & $1[23]$ & & $1[44]$ & $1[44]$ & & & & & & \\
\hline Depression history & $1[26]$ & & & & & & & & & \\
\hline \multicolumn{11}{|l|}{ Anxiety } \\
\hline Hospital Anxiety and Depression Scale (HADS) & & & $2[43,45]$ & & $1[73]$ & & & & & \\
\hline \multicolumn{11}{|l|}{ Positive and negative affect } \\
\hline Positive and Negative Affect Scale (PANAS) & & & & & & & & $1[46]$ & & \\
\hline \multicolumn{11}{|l|}{ Coping } \\
\hline $\begin{array}{l}\text { Brief COPE- Engagement Coping, Disengagement } \\
\text { Coping, Venting and Self-Distraction }\end{array}$ & & & $1[28]$ & & & & & & & \\
\hline $\begin{array}{l}\text { Brief COPE- active/positive coping and passive/ } \\
\text { negative coping }\end{array}$ & $\begin{array}{l}2[23 \\
25]\end{array}$ & & & & & & & & & \\
\hline $\begin{array}{l}\text { Family Crisis Oriented Personal Evaluation Scale (F- } \\
\text { COPES) }\end{array}$ & $1[47]$ & $1[47]$ & & & & & & & & \\
\hline Ways of Coping-Preparedness & $1[41]$ & & & & & & $1[41]$ & & & \\
\hline \multicolumn{11}{|l|}{ Confidence and self-efficacy } \\
\hline Question- confidence about remaining cancer free & & & & & & & & & $1[13]$ & \\
\hline Health efficacy & $1[35]$ & & & & & & & & & \\
\hline Rosenberg Self-Esteem Scale & & & & & & $1[39]$ & & & & \\
\hline Rosenbaum Self-Control Schedule & & & & & & $1[39]$ & & & & \\
\hline \multicolumn{11}{|l|}{ Spirituality } \\
\hline $\begin{array}{l}\text { Functional Assessment of Chronic Illness Therapy- } \\
\text { Spiritual Well-being Scale }\end{array}$ & $1[23]$ & & & & & & & & & \\
\hline Religious Coping- negative coping subscale & $1[48]$ & & & & & & & & & \\
\hline Systems of Belief Inventory & $\begin{array}{l}2[26, \\
49]\end{array}$ & & & & & & & & & \\
\hline \multicolumn{11}{|l|}{ Optimism } \\
\hline Life Orientation Test & $\begin{array}{l}2[23, \\
38]\end{array}$ & & $1[28]$ & & & & & & $1[13]$ & \\
\hline The Minnesota Multiphasic Personality Inventory & & $1[50]$ & & & & & & & & \\
\hline
\end{tabular}


Table 5 Frequency of psychosocial determinant measures per individual QoL measure (Continued)

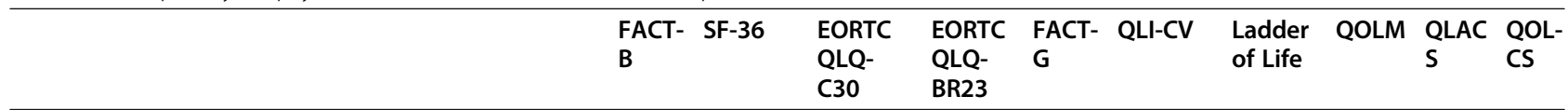

(MMPI) - optimism-pessimism (PSM) scale

\section{Future perspectives and appraisal}

Mishel Uncertainty in Illness Scale

Appraisal of illness

Power as Knowing Participation in Change Tool

Self-Transcendence Scale

Recurrence information, likelihood and worry about recurrence, decision regret

Fear of Progression Questionnaire

Concerns of Recurrence Scale

Vulnerability- fears about recurrence

Impact of Events

Impact of Events Survey

Illness Intrusiveness Rating Scale

Impact of Cancer

\section{Stress}

Post-traumatic Stress Disorder Checklist $\quad 1$ [54]

Omega Screening Questionnaire

Life Stress Scale

Amount of stress and perceived handling of stress

FACT-B additional concerns

Urban Life Stress Scale

The Family Communication Scale of the Family

Adaptability and Cohesion Evaluation (FACES-IV) and

the Family Avoidance of Communication about

Cancer (FACC)

\section{Post-traumatic Growth}

Post-traumatic Growth Inventory

\section{Cognitive Symptoms}

Cognitive Symptoms Checklist-Work

\section{Work Limitations}

Work Limitations Questionnaire

\section{Healthcare System}

Patient-doctor relationship, comfort in healthcare system and diagnostic care delay

\section{$2[32,51]$}

$1[38]$

1 [51]

$1[51]$

$1[26]$

1 [29] 1 [29]

$1[30]$

$1[52]$
$1[37]$

$1[23]$

$1[53]$

$1[33]$

$1[33]$

$1[35]$

$1[47] \quad 1[47]$

$1[47] \quad 1[47]$

$1[47] \quad 1[47]$

FACT-B Functional Assessment of Cancer - Breast Cancer, SF-36 Medical Outcomes Study Short Form, EORTC QLQ-C30 The European Organisation of Research and Treatment of Cancer Quality of Life Questionnaire, QLQ-BR23 The European Organisation of Research and Cancer Treatment Quality of Life Questionnaire - Breast Cancer, FACT-G Functional Assessment of Cancer Therapy - General, QLI-CV Quality of Life Index - Cancer Version, QoL-M Quality of Life Measurement, QLACS Quality of Life in Adult Cancer Survivors, QOL-CS Quality of Life Cancer Survivor Version, GLSS Global Life Satisfaction Scale

However there were some limitations to this review process. It is feasible that despite an extensive search of multiple databases, some relevant papers may have been missed. Not all abstracts were screened by two independent reviewers; $75 \%$ were screened. However the adaption of the inclusion/exclusion criteria by the two independent reviewers as part of the scoping review iterative process allowed for a more focused review by alleviating any potential ambiguity, given the broad research question [20]. There was also no quality appraisal or meta-analysis of the included studies undertaken, but again is not 
deemed to be part of the scoping review process [19].

Recently there has been an emphasis on developing more patient-centered care in breast cancer survivors and using an individual's psychological needs as a guide for psychosocial treatment selection rather than their diagnostic or medical treatment [111]. Understanding the influence of psychosocial determinants on QoL in breast cancer survivors potentially helps to enable the development of more personalised and tailored intervention strategies and support services to reduce long term physical and psychological morbidity. The identified psychosocial determinants can be mapped to evidence based psychosocial treatments such as Cognitive and Behavioral Cancer Stress Management to provide patients with skills to live well with breast cancer and/or improve QoL [112].

\section{Conclusion}

This review has identified several psychosocial determinants of QoL in breast cancer survivors. The overall consistency of the associations found between the various psychosocial variables and QoL, regardless of the measures used, provides a reasonably clear picture of the influence of individual psychosocial determinants on
QoL in breast cancer survivors. The fact that these associations do not depend on the specific measures used adds validity to the findings. However this review has also highlighted a clear need to standardise measures of both QoL and individual psychosocial determinants, potentially through expert consensus groups, in order to be able to evaluate the impact of psychosocial determinants on QoL systematically and to compare results across studies. Further research also needs to be undertaken in health care settings, outside of the USA; given that psychosocial determinants and QoL itself may in fact be influenced by the organisation and availability of follow-up clinical and supportive care. Future studies should also use a prospective or longitudinal design to monitor change and understand the complexity and variety of influences on QoL long-term. By improving the quality of evidence on this topic there is the potential to also improve the quality of follow-up care in breast cancer survivors.

\section{Abbreviations}

QoL: Quality-of-life; FACT-B: Functional Assessment of Cancer - Breast Cancer; FACT-G: Functional Assessment of Cancer Therapy - General; SF-36: Medical Outcomes Study Short Form; EORTC QLQ-C30: The European Organisation of Research and Treatment of Cancer Quality of Life Questionnaire; QLQ-

BR23: The European Organisation of Research and Cancer Treatment Quality

\section{Appendix}

Table 6 Database search criteria

\begin{tabular}{ll}
\hline PubMed & \\
Survivors(MeSH Terms) & breast neoplasms (MeSH Terms) \\
OR survivor*(Title/Abstract) & OR Breast cancer(Title/Abstract)
\end{tabular}

\section{EMBASE}

'survivors'/exp.

OR survivor*:to,ab 'breast cancer'/exp.

OR ((breast NEXT/1 cancer):ti,ab)

OR ((breast NEXT/1 neoplasm*):ti,ab)

$$
\begin{aligned}
& \text { QOL (MeSH Terms) } \\
& \text { OR HRQOL } \\
& \text { OR physical } \\
& \text { OR emotional } \\
& \text { OR functional } \\
& \text { OR social }
\end{aligned}
$$

women

OR female (1)

women OR female

OR HRQOL

OR physical

OR emotional

OR functional

OR social

QOL

OR HRQOL

OR Physical

OR Emotional

OR Functiona

OR Social

QOL

OR HRQOL

OR Physical

OR Emotional

OR Functional

OR Social 
of Life Questionnaire - Breast Cancer; QLI-CV: Quality of Life Index - Cancer Version; QoL-M: Quality of Life Measurement; QLACS: Quality of Life in Adult Cancer Survivors; QOL-CS: Quality of Life Cancer Survivor Version; GLSS: Global Life Satisfaction Scale

\section{Acknowledgements}

We would like to thank Lamorna, Alenka, Isadora and Cathy for their help in reviewing abstracts.

\section{Authors' contributions}

$M C$ and $C C$ were involved in the concept and design of the study. $M C$ was the primary reviewer. $M C, K B, C M K, L S$ and $C C$ were involved in

interpretation of the findings. $\mathrm{MC}$ wrote the first draft of the manuscript and $\mathrm{KB}, \mathrm{CMK}, \mathrm{LS}$ and CC contributed to subsequent drafts. All authors have read and approved the manuscript.

\section{Funding}

CC and KB were funded by the Health Research Board (HRB), Research Leaders Award (HRB RL-2015-1579) and the Marie Keating Foundation (CTRI AL-IE 17-16). MC was funded by the Marie Keating Foundation (CTRIAL-IE 17-16) and also by the HRB Summer Scholarship programme. The HRB and Marie Keating Foundations had no role in the design, methods, analysis of this study, or in the preparation of this article.

\section{Availability of data and materials \\ Not applicable}

\section{Ethics approval and consent to participate}

Not applicable

\section{Consent for publication}

Not applicable

\section{Competing interests}

The authors declare that they have no competing interests.

\section{Author details}

'Division of Population Health Sciences, Royal College of Surgeons in Ireland, Beaux Lane House, Mercer Street, Dublin 2, Ireland. ${ }^{2}$ Mater Misericordiae University Hospital, Dublin 1, Ireland. ${ }^{3}$ Population Health Sciences Institute, Newcastle University Centre for Cancer, Newcastle University, Newcastle, UK.

\section{Received: 17 February 2020 Accepted: 8 September 2020}

Published online: 02 October 2020

\section{References}

1. Allemani C, Matsuda T, Di Carlo V, Harewood R, Matz M, Niksic M, et al. Global surveillance of trends in cancer survival 2000-14 (CONCORD-3): analysis of individual records for 37513025 patients diagnosed with one of 18 cancers from 322 population-based registries in 71 countries. Lancet. 2018;391(10125):1023-75

2. Sharp L, Deady S, Gallagher P, Molcho M, Pearce A, Alforque Thomas A, et al. The magnitude and characteristics of the population of cancer survivors: using population-based estimates of cancer prevalence to inform service planning for survivorship care. BMC Cancer. 2014;14(1):767.

3. WHO. Cancer incidence and mortality statistics worldwide and by region http://gco.iarc.fr/today/data/factsheets/cancers/20-Breast-fact-sheet.pdf: The Global Cancer Observatory. 2018.

4. Bell K, Ristovski-Slijepcevic S. Cancer survivorship: why labels matter. J Clin Oncol. 2013;31(4):409-11.

5. Denlinger CS, Carlson RW, Are M, Baker KS, Davis E, Edge SB, et al. Survivorship: introduction and definition. Clinical practice guidelines in oncology. J Natl Compr Cancer Netw. 2014;12(1):34-45.

6. Keesing S, Rosenwax L, McNamara B. A call to action: The need for improved service coordination during early survivorship for women with breast cancer and partners. Women Health. 2019;59(4):406-19.

7. Costanzo ES, Lutgendorf SK, Mattes ML, Trehan S, Robinson CB, Tewfik F, et al. Adjusting to life after treatment: distress and quality of life following treatment for breast cancer. Br J Cancer. 2007:97(12):1625-31.

8. Stanton AL. What happens now? Psychosocial care for cancer survivors after medical treatment completion. J Clin Oncol. 2012;30(11):1215-20.
9. Institute of Medicine Committee on Psychosocial Services to Cancer Patients/Families in a Community S. The National Academies Collection: Reports funded by National Institutes of Health. In: Adler NE, Page AEK, editors. Cancer Care for the Whole Patient: Meeting Psychosocial Health Needs. Washington (DC): National Academies Press (US) National Academy of Sciences; 2008.

10. Macleod J, Davey SG. Psychosocial factors and public health: a suitable case for treatment? J Epidemiol Community Health. 2003;57(8):565.

11. Walker J, Hansen CH, Martin P, Symeonides S, Ramessur R, Murray G, et al. Prevalence, associations, and adequacy of treatment of major depression in patients with cancer: a cross-sectional analysis of routinely collected clinical data. Lancet Psychiatry. 2014;1(5):343-50.

12. Bloom JR, Petersen DM, Kang SH. Multi-dimensional quality of life among long-term (5+ years) adult cancer survivors. Psychooncology. 2007;16(8): 691-706.

13. Carver CS, Smith RG, Petronis VM, Antoni MH. Quality of life among longterm survivors of breast cancer: different types of antecedents predict different classes of outcomes. Psycho-Oncology. 2006;15(9):749-58.

14. Doege D, Thong MS, Koch-Gallenkamp L, Bertram H, Eberle A, Holleczek B, et al. Health-related quality of life in long-term disease-free breast cancer survivors versus female population controls in Germany. Breast Cancer Res Treat. 2019;175(2):499-510.

15. Kendall AR, Mahue-Giangreco M, Carpenter CL, Ganz PA, Bernstein L. Influence of exercise activity on quality of life in long-term breast cancer survivors. Qual Life Res. 2005;14(2):361-71.

16. Bower JE, Meyerowitz BE, Desmond KA, Bernaards CA, Rowland JH, Ganz PA. Perceptions of positive meaning and vulnerability following breast cancer: predictors and outcomes among long-term breast cancer survivors. Ann Behav Med. 2005;29(3):236-45.

17. Mols F, Vingerhoets AJJM, Coebergh JW, van de Poll-Franse LV. Quality of life among long-term breast cancer survivors: a systematic review. Eur J Cancer. 2005:41(17):2613-9.

18. Munn Z, Peters MDJ, Stern C, Tufanaru C, McArthur A, Aromataris E. Systematic review or scoping review? Guidance for authors when choosing between a systematic or scoping review approach. BMC Med Res Methodol. 2018;18(1):143.

19. Arksey H, O'Malley L. Scoping studies: towards a methodological framework. Int J Soc Res Methodol. 2005;8(1):19-32.

20. Levac D, Colquhoun H, O'Brien KK. Scoping studies: advancing the methodology. Implement Sci. 2010;5(1):69.

21. Brady MJ, Cella DF, Mo F, Bonomi AE, Tulsky DS, Lloyd SR, et al. Reliability and validity of the functional assessment of cancer therapy-breast qualityof-life instrument. J Clin Oncol. 1997;15(3):974-86.

22. Aaronson NK, Ahmedzai S, Bergman B, Bullinger M, Cull A, Duez NJ, et al. The European Organization for Research and Treatment of Cancer QLQ-C30: a quality-of-life instrument for use in international clinical trials in oncology. J Natl Cancer Inst. 1993;85(5):365-76.

23. Goyal NG, Levine BJ, Van Zee KJ, Naftalis E, Avis NE. Trajectories of quality of life following breast cancer diagnosis. Breast Cancer Res Treat. 2018;169(1): 163-73.

24. Deshields T, Tibbs T, Fan M-y, Taylor M. Differences in patterns of depression after treatment for breast cancer. Psycho-Oncology. 2006;15(5): 398-406.

25. Paek M-S, Ip EH, Levine B, Avis NE. Longitudinal reciprocal relationships between quality of life and coping strategies among women with breast cancer. Ann Behav Med. 2016;50(5):775-83.

26. Janz NK, Friese CR, Li Y, Graff JJ, Hamilton AS, Hawley ST. Emotional wellbeing years post-treatment for breast cancer: prospective, multi-ethnic, and population-based analysis. J Cancer Surviv. 2014;8(1):131-42.

27. Bellizzi KM, Smith AW, Reeve BB, Alfano CM, Bernstein L, Meeske $K$, et al. Posttraumatic growth and health-related quality of life in a racially diverse cohort of breast cancer survivors. J Health Psychol. 2010;15(4):615-26.

28. Durá-Ferrandis E, Mandelblatt JS, Clapp J, Luta G, Faul L, Kimmick G, et al. Personality, coping, and social support as predictors of long-term quality-oflife trajectories in older breast cancer survivors: Calgb protocol 369901 (alliance). Psycho-Oncology. 2017;26:1914.

29. Koch L, Bertram H, Eberle A, Holleczek B, Schmid-Hopfner S, Waldmann A, et al. Fear of recurrence in long-term breast cancer survivors-still an issue. Results on prevalence, determinants, and the association with quality of life and depression from the cancer survivorship--a multi-regional populationbased study. Psychooncology. 2014;23(5):547-54. 
30. Taylor T, Huntley E, Sween J, Makambi K, Mellman T, Williams C, et al. An exploratory analysis of fear of recurrence among African-American breast cancer survivors. Int J Behav Med. 2012;19(3):280-7.

31. Ho SSM, So WKW, Leung DYP, Lai ETL, Chan CWH. Anxiety, depression and quality of life in Chinese women with breast cancer during and after treatment: a comparative evaluation. Eur J Oncol Nurs. 2013;17(6):877-82.

32. Sammarco A, Konecny LM. Quality of life, social support, and uncertainty among Latina breast cancer survivors. Oncol Nurs Forum. 2008;35(5):844-9.

33. Ashing-Giwa KT, Lim JW. Predicting physical quality of life among a multiethnic sample of breast cancer survivors. Qual Life Res. 2010;19(6):789-802

34. Cheng H, Sit JW, Chan CW, So WK, Choi KC, Cheng KK. Social support and quality of life among Chinese breast cancer survivors: findings from a mixed methods study. Eur J Oncol Nurs. 2013;17(6):788-96.

35. DiSipio T, Hayes S, Newman B, Janda M. What determines the health-related quality of life among regional and rural breast cancer survivors? Aust N Z J Public Health. 2009;33(6):534-9

36. Huang $\mathrm{C}-\mathrm{Y}$, Hsu M-C. Social support as a moderator between depressive symptoms and quality of life outcomes of breast cancer survivors. Eur J Oncol Nurs. 2013;17(6):767-74.

37. Lewis JA, Manne SL, DuHamel KN, Vickburg SM, Bovbjerg DH, Currie V, et al. Social support, intrusive thoughts, and quality of life in breast cancer survivors. J Behav Med. 2001;24(3):231-45.

38. Northouse LL, Caffey M, Deichelbohrer L, Schmidt L, Guziatek-Trojniak L, West $S$, et al. The quality of life of African American women with breast cancer. Res Nurs Health. 1999;22(6):449-60.

39. Pedro LW. Quality of life for long-term survivors of cancer: influencing variables. Cancer Nurs. 2001;24(1):1-11.

40. Edib Z, Kumarasamy V, binti Abdullah N, Rizal AM, Al-Dubai SAR. Most prevalent unmet supportive care needs and quality of life of breast cancer patients in a tertiary hospital in Malaysia. Health Qual Life Outcomes. 2016;14(1):26.

41. Avis NE, Crawford S, Manuel J. Quality of life among younger women with breast cancer. J Clin Oncol. 2005;23(15):3322-30.

42. Begovic-Juhant A, Chmielewski A, Iwuagwu S, Chapman LA. Impact of body image on depression and quality of life among women with breast cancer. J Psychosoc Oncol. 2012;30(4):446-60.

43. Cheng ASK, Lau LOC, Ma YNH, Ngai RH, Fong SSL. Impact of cognitive and psychological symptoms on work productivity and quality of life among breast cancer survivors in Hong Kong. Hong Kong J Occup Ther. 2016;28(1):15-23.

44. Kim SH, Son BH, Hwang SY, Han W, Yang JH, Lee S, et al. Fatigue and depression in disease-free breast cancer survivors: prevalence, correlates, and association with quality of life. J Pain Symptom Manag. 2008;35(6):644-55.

45. Akechi T, Momino K, Miyashita M, Sakamoto N, Yamashita H, Toyama T. Anxiety in disease-free breast cancer patients might be alleviated by provision of psychological support, not of information. Jpn J Clin Oncol. 2015;45(10):929-33.

46. Kessler TA. Contextual variables, emotional state, and current and expected quality of life in breast cancer survivors. Oncol Nurs Forum. 2002;29(7):1109-16.

47. Paek MS, Lim JW. Understanding the stress process of Chinese- and KoreanAmerican breast cancer survivors. J Immigr Minor Health. 2016;18(5):1159-67.

48. Manning-Walsh J. Spiritual struggle: effect on quality of life and life satisfaction in women with breast cancer. J Holist Nurs. 2005;23(2):120-40 discussion 41-4.

49. Wildes KA, Miller AR, de Majors SSM, Ramirez AG. The religiosity/spirituality of Latina breast cancer survivors and influence on health-related quality of life. Psycho-Oncology. 2009;18(8):831-40.

50. Petersen LR, Clark MM, Novotny P, Kung S, Sloan JA, Patten CA, et al. Relationship of optimism-pessimism and health-related quality of life in breast cancer survivors. J Psychosoc Oncol. 2008;26(4):15-32.

51. Farren AT. Power, uncertainty, self-transcendence, and quality of life in breast cancer survivors. Nurs Sci Q. 2010;23(1):63-71.

52. Ganz PA, Greendale GA, Petersen L, Kahn B, Bower JE. Breast cancer in younger women: reproductive and late health effects of treatment. J Clin Oncol. 2003;21(22):4184-93.

53. Bouskill K, Kramer M. The impact of cancer and quality of life among long-term survivors of breast cancer in Austria. Support Care Cancer. 2016;24(11):4705-12.

54. Morrill EF, Brewer NT, O'Neill SC, Lillie SE, Dees EC, Carey LA, et al. The interaction of post-traumatic growth and post-traumatic stress symptoms in predicting depressive symptoms and quality of life. Psycho-Oncology. 2008; 17(9):948-53.

55. Lins L, Carvalho FM. SF-36 total score as a single measure of health-related quality of life: scoping review. SAGE Open Med. 2016;4:2050312116671725.
56. Edib Z, Kumarasamy V, Abdullah N, Rizal AM, Al-Dubai SAR, Binti Abdullah N. Most prevalent unmet supportive care needs and quality of life of breast cancer patients in a tertiary hospital in Malaysia. Health Qual Life Outcomes. 2016;14:1-10.

57. Sprangers MA, Groenvold M, Arraras Jl, Franklin J, te Velde A, Muller M, et al. The European Organization for Research and Treatment of Cancer breast cancer-specific quality-of-life questionnaire module: first results from a three-country field study. J Clin Oncol. 1996;14(10):2756-68.

58. Ferrans CE. Development of a quality of life index for patients with cancer. Oncol Nurs Forum. 1990;17(3 Suppl):15-9 discussion 20-1.

59. Cantril $H$. The pattern of human concerns. New Brunswick: Rutgers University Press; 1965.

60. Sohl SJ, Levine B, Avis NE. Evaluation of the Quality of Life in Adult Cancer Survivors (QLACS) scale for early post-treatment breast cancer survivors. Qual Life Res. 2015;24(1):205-12.

61. Ferrell BR, Dow KH, Grant M. Measurement of the quality of life in cancer survivors. Qual Life Res. 1995;4(6):523-31.

62. Sherbourne CD, Stewart AL. The MOS social support survey. Soc Sci Med. 1991;32(6):705-14.

63. Cohen S., Underwood LG, Gottlieb BH. Social support measurement and intervention: a guide for health and social scientists. 2000. New York.

64. Sarason IG, Sarason BR, Shearin EN, Pierce GR. A brief measure of social support: practical and theoretical implications. J Soc Pers Relat. 1987;4(4):497-510.

65. Cohen S, Doyle WJ, Skoner DP, Rabin BS, Gwaltney JM Jr. Social ties and susceptibility to the common cold. JAMA. 1997;277(24):1940-4.

66. Northouse LL. Social support in patients' and husbands' adjustment to breast cancer. Nurs Res. 1988;37(2):91-5.

67. Smilkstein G. The family APGAR: a proposal for family function test and its use by physicians. J Fam Pract. 1978;6(6):1231-9.

68. Norbeck JS. Social support: a model for clinical research and application Adv Nurs Sci. 1981;3(4):43.

69. McElduff P, Boyes A, Zucca A, Girgis A. Supportive Care Needs Survey: A guide to administration, scoring and analysis. Centre for Health Research \& Psycho-oncology; 2004.

70. Schag CA, Ganz PA, Polinsky ML, Fred C, Hirji K, Petersen L. Characteristics of women at risk for psychosocial distress in the year after breast cancer. J Clin Oncol. 1993;11(4):783-93.

71. Radloff LS. The CES-D scale:a self-report depression scale for research in the general population. Appl Psychol Meas. 1977;1(3):385-401.

72. Zigmond AS, Snaith RP. The hospital anxiety and depression scale. Acta Psychiatr Scand. 1983;67(6):361-70.

73. Beck AT, Steer RA, Ball R, Ranieri WF. Comparison of beck depression inventories-IA and-II in psychiatric outpatients. J Pers Assess. 1996; 67(3):588-97.

74. Watson D, Clark LA, Tellegen A. Development and validation of brief measures of positive and negative affect: the PANAS scales. J Pers Soc Psychol. 1988;54:1063.

75. Carver CS. You want to measure coping but your protocol's too long: consider the brief COPE. Int J Behav Med. 1997;4:92.

76. McCubbin H, Larsen A, Olson D. Family crisis orientated personal evaluation scales (FCOPES). In: McCubbin H, Thompson Al, editors. Family assessment inventories for research and practice; 1987. p. 193-207.

77. Dunkel-Schetter C, Feinstein LG, Taylor SE, Falke RL. Patterns of coping with cancer. Health Psychol. 1992;11(2):79-87.

78. Becker H, Stuifbergen A, Oh HS, Hall S. Self-rated abilities for health practices: a health self-efficacy measure. Health Values. 1993;17(5):42-50.

79. Rosenberg M, Kaplan H. Social psychology of the self-concept. Chicago: Harlan Davidson; 1982

80. Cope DG, Olson K, Humenick SS. Self-esteem and the practice of breast selfexamination. West J Nurs Res. 1992;14(5):618-31.

81. Peterman AH, Fitchett G, Brady MJ, Hernandez L, Cella D. Measuring spiritual well-being in people with cancer: the functional assessment of chronic illness therapy--Spiritual Well-being Scale (FACIT-Sp). Ann Behav Med. 2002; 24(1):49-58.

82. Pargament Kl, Smith BW, Koenig HG, Perez L. Patterns of positive and negative religious coping with major life stressors. J Sci Study Relig. 1998; 37(4):710-24.

83. Holland JC, Kash KM, Passik S, Gronert MK, Sison A, Lederberg M, et al. A brief spiritual beliefs inventory for use in quality of life research in lifethreatening illness. Psycho-Oncology. 1998;7(6):460-9.

84. Scheier MF, Carver CS. Optimism, coping, and health: assessment and implications of generalized outcome expectancies. Health Psychol. 1985;4(3):219-47. 
85. Colligan RC, Offord KP, Malinchoc M, Schulman P, Seligman MEP. CAVEing the MMPI for an optimism-pessimism scale: Seligman's attributional model and the assessment of explantory style. J Clin Psychol. 1994;50:71-95.

86. Mishel MH. Uncertainty in illness. Image. 1988;20:225-32.

87. Oberst MT. Appraisal of illness scale: manual for use. Detroit: Wayne State University; 1991.

88. Barrett EA, Caroselli C. Methodological ponderings related to the power as knowing participation in change tool. Nurs Sci Q. 1998;11(1):17-22.

89. Reed PG. Self-transcendence scale. Tucson: University of Arizona; 1987.

90. Hawley ST, Janz NK, Hamilton A, Griggs JJ, Alderman AK, Mujahid M, et al. Latina patient perspectives about informed treatment decision making for breast cancer. Patient Educ Couns. 2008;73(2):363-70.

91. Herschbach P, Berg P, Dankert A, Duran G, Engst-Hastreiter U, Waadt S, et al. Fear of progression in chronic diseases: psychometric properties of the Fear of Progression Questionnaire. J Psychosom Res. 2005;58(6):505-11.

92. Vickberg SM. The Concerns About Recurrence Scale (CARS): a systematic measure of women's fears about the possibility of breast cancer recurrence. Ann Behav Med. 2003;25(1):16-24

93. Ganz PA, Rowland JH, Desmond K, Meyerowitz BE, Wyatt GE. Life after breast cancer: understanding women's health-related quality of life and sexual functioning. J Clin Oncol. 1998;16(2):501-14.

94. Horowitz M, Wilner N, Alvarez W. Impact of event scale: a measure of subjective stress. Psychosom Med. 1979;41(3):209-18.

95. Devins GM. Using the illness intrusiveness ratings scale to understand healthrelated quality of life in chronic disease. J Psychosom Res. 2010;68(6):591-602.

96. Zebrack BJ, Ganz PA, Bernaards CA, Petersen L, Abraham L. Assessing the impact of cancer: development of a new instrument for long-term survivors. Psychooncology. 2006;15(5):407-21.

97. Weathers FW, Huska JA, TM. K. PCL-C for DSM-IV. Boston: National Center for PTSD_Behavioral Science Division; 1991.

98. Mood D, Bickes J. Strategies to enhance self-care in radiation therapy. Oncol Nurs Forum (Supplement). 1989;16:143.

99. Ashing-Giwa KT, Padilla GV, Tejero JS, Kim J. Breast cancer survivorship in a multiethnic sample: challenges in recruitment and measurement. Cancer. 2004;101(3):450-65.

100. Ashing-Giwa K, Ganz PA, Petersen L. Quality of life of African-American and white long term breast carcinoma survivors. Cancer. 1999:85(2):418-26.

101. Olson D. FACES IV and the Circumplex Model: validation study. J Marital Fam Ther. 2011;37(1):64-80.

102. Mallinger JB, Griggs JJ, Shields CG. Family communication and mental health after breast cancer. Eur J Cancer Care. 2006;15(4):355-61.

103. Tedeschi RG, Calhoun LG. The posttraumatic growth inventory: measuring the positive legacy of trauma. J Trauma Stress. 1996;9(3):455-71.

104. Ottati A, Feuerstein M. Brief self-report measure of work-related cognitive limitations in breast cancer survivors. J Cancer Surviv. 2013;7(2):262-73.

105. Lerner D, Amick BC 3rd, Rogers WH, Malspeis S, Bungay K, Cynn D. The work limitations questionnaire. Med Care. 2001;39(1):72-85.

106. DiMatteo MR, Hays RD, Gritz ER, Bastani R, Crane L, Elashoff R, et al. Patient adherence to cancer control regimens: scale development and initial validation. Psychol Assess. 1993;5(1):102-12.

107. Chopra I, Kamal KM. A systematic review of quality of life instruments in long-term breast cancer survivors. Health Qual Life Outcomes. 2012;10:14.

108. Osoba D, Rodrigues G, Myles J, Zee B, Pater J. Interpreting the significance of changes in health-related quality-of-life scores. J Clin Densitom. 1998;16:139.

109. Webster K, Cella D, Yost K. The Functional Assessment of Chronic Illness Therapy (FACIT) Measurement System: properties, applications, and interpretation. Health Qual Life Outcomes. 2003;1:79.

110. Hullmann SE, Robb SL, Rand KL. Life goals in patients with cancer: a systematic review of the literature. Psycho-Oncology. 2016;25(4):387-99.

111. Garchinski CM, DiBiase A-M, Wong RK, Sagar SM. Patient-centered care in cancer treatment programs: the future of integrative oncology through psychoeducation. Future Oncol. 2014;10(16):2603-14.

112. Gudenkauf LM, Ehlers SL. Psychosocial interventions in breast cancer survivorship care. Breast. 2018;38:1-6.

\section{Publisher's Note}

Springer Nature remains neutral with regard to jurisdictional claims in published maps and institutional affiliations.

Ready to submit your research? Choose BMC and benefit from:

- fast, convenient online submission

- thorough peer review by experienced researchers in your field

- rapid publication on acceptance

- support for research data, including large and complex data types

- gold Open Access which fosters wider collaboration and increased citations

- maximum visibility for your research: over $100 \mathrm{M}$ website views per year

At BMC, research is always in progress.

Learn more biomedcentral.com/submissions 